INEEL/EXT-2000-00207

February 2000

\title{
Proceedings from the Workshop on Phytoremediation of Inorganic Contaminants
}

November 30 - December 2, 1999 Argonne National Laboratory Chicago, Illinois

Sponsored by U.S. Department of Energy Subsurface Contaminants Focus Area 


\title{
Proceedings from the Workshop on Phytoremediation of Inorganic Contaminants
}

\author{
Sponsored by \\ U.S. Department of Energy - Subsurface Contaminants Focus Area \\ In cooperation with \\ Idaho National Engineering and Environmental Laboratory, \\ Argonne National Laboratory and \\ Envirolssues \\ Published February 2000
}

Idaho National Engineering and Environmental Laboratory Idaho Falls, Idaho 83415

Prepared for the U.S. Department of Energy Assistant Secretary for Environmental Management Under DOE Idaho Operations Office Contract DE-AC07-99ID13727 
TABLE OF CONTENTS

Workshop on Phytoremediation of Inorganic Contaminants

Section

Title

Page

$1.0 \quad$ Introduction

$2.0 \quad$ Workshop Structure 1

3.0 Summary of Discussions 3

4.0 Lessons Learned 13

$\begin{array}{lll}\text { 5.0 Recommendations and Conclusions } & 14\end{array}$

\section{Appendix}

A Groundwater Applications Report A-1

B Removal from Soil (Phytoextraction) Report $\quad$ B-1

C Stabilization/Sequestration in Soil Report $\quad$ C-1

D Phytoremediation Monitoring Report D-1

E Phytoremediation Demonstration Site at ANL-E E-1

F Roster of Participants $\quad$ F-1

G Supporting Documentation G-1

H Definitions $\quad$ H-1

I Sources of Additional Information I-1 


\section{PROCEEDINGS FROM THE WORKSHOP ON PHYTOREMEDIATION OF INORGANIC CONTAMINANTS}




\section{PROCEEDINGS FROM THE WORKSHOP ON PHYTOREMEDIATION OF INORGANIC CONTAMINANTS}

\subsection{INTRODUCTION}

The Metals and Radionuclides Product Line of the U.S. Department of Energy (DOE) Subsurface Contaminants Focus Area (SCFA) is responsible for the development of technologies and systems that reduce the risk and cost of remediation of radionuclide and hazardous metal contamination in soils and groundwater. The rapid and efficient remediation of these sites and the areas surrounding them represents a technological challenge. Phytoremediation, the use of living plants to cleanup contaminated soils, sediments, surface water and groundwater, is an emerging technology that may be applicable to the problem. The use of phytoremediation to cleanup organic contamination is widely accepted and is being implemented at numerous sites. This workshop was held to initiate a discussion in the scientific community about whether phytoremediation is applicable to inorganic contaminants, such as metals and radionuclides, across the DOE complex.

The Workshop on Phytoremediation of Inorganic Contaminants was held at Argonne National Laboratory from November 30 through December 2, 1999. The purpose of the workshop was to provide SCFA and the DOE Environmental Restoration Program with an understanding of the status of phytoremediation as a potential remediation technology for DOE sites. The workshop was expected to identify data gaps, technologies ready for demonstration and deployment, and to provide a set of recommendations for the further development of these technologies. More specifically, the objectives of the workshop were to:

- Determine the status of the existing baseline, including technological maturation,

- Identify areas for future potential research,

- Identify the key issues and recommendations for issue resolution,

- Recommend a strategy for maturing key aspects of phytoremediation,

- Improve communication and collaboration among organizations currently involved in phytoremediation research, and

- Identify technical barriers to making phytoremediation commercially successful in more areas.

\subsection{WORKSHOP STRUCTURE}

The workshop was designed to function as an organized brainstorming session by offering a forum that would facilitate communications between technical disciplines and levels of research and development that might not otherwise occur. The workshop was comprised of invitation-only participants drawn from across the DOE complex, the U.S. Environmental Protection Agency, the U.S. Department of Agriculture, the Department of Defense, academia, industry, and regulatory agencies. Participants represented a wide range of technical disciplines including agronomy, soil chemistry, geochemistry, engineering, biology, chemistry, physiology, toxicology, and hydrology. Participant 
experience ranged from laboratory bench-scale work to field work and business enterprises.

Prior to convening at Argonne, the workshop organizers in conjunction with experts in the field identified four primary areas of phytoremediation for examination. These four categories provided a structure for the working groups that were led by team leads (also designated prior to the workshop). The working groups and team leads are identified below:

- Groundwater Applications - led by Steve Rock of U.S. EPA's Superfund Innovative Technology Evaluation (SITE) program.

- Removal from Soils - led by Mike Kuperberg of Florida State University.

- Stabilization and Sequestration - led by Cal Ainsworth of Pacific Northwest National Laboratories.

- Monitoring - led by Jody Waugh of Roy F. Weston, Inc., Grand Junction Office

The workshop was organized to include a range of disciplines and experience in each group while ensuring an environment conducive to open discussion. Each of the four discussion groups consisted of no more than fifteen members and the team leader, and was assisted by a facilitator and a recorder. Brainstorming sessions were followed by presentations by each group that addressed key areas of research and recommendations. These presentations were made to the entire group of workshop participants so that all participants had a thorough understanding of discussions that had taken place in each working group. Workshop participants from all groups were asked to comment on each group's presentation. This discussion was useful as it helped the groups to clarify specific ideas about research and application. After the presentations and comments, the working groups reconvened to work through revisions and develop a summary. Each team lead drafted the summaries with support from a facilitator. The group summaries reflect the collective views of each of the teams including areas of consensus and disagreement. The summaries include each group's evaluation of the current state of the art and recommendations for future investment in the area of phytoremediation. The complete group summaries are included in Appendices A through D

A tour was also taken of the 317/319 Areas at Argonne National Laboratory - East, where the deployment of phytoremediation is the final action to complete corrective action for removal of tritium and VOCs in this area. The installed system consists of plantings of shallow-rooted hybrid willows and special deep-rooted hybrid poplars. This system will prevent the further generation of contaminated groundwater in the source area by degrading the contaminants, and will also prevent the further migration of these plumes by removing groundwater from saturated zones downgradient from the source area. A detailed discussion of this deployment is included in Appendix E 


\subsection{SUMMARY OF DISCUSSIONS}

This section contains an executive summary of the discussion in each of the four working groups. The complete group reports are included in Appendices A, B, C, and D.

\subsection{Groundwater Applications}

Phytoremediation of groundwater is one of the more advanced applications of the suite of phytoremediation technologies. There are more sites installed and more experience in the application of phytoremediation to manage groundwater than in metals uptake or in degradation of organic compounds in soil.

The limit of depth to groundwater for phytoremediation applications is very dependent on soil type and soil conditions. Non-engineered phytoremediation systems, for example, are dependent on site stratigraphy. There was consensus that a 30 -foot depth is readily possible, and that the depth limit could be extended to 50 feet with some modifications. Wetlands, greenhouses, and hydroponics also can be used to extend the possible depth to which phytoremediation can be applied, as water also can be pumped up and circulated through plants in greenhouses.

Contaminant uptake rates are a function of plant water use. Some of the factors known to determine rates of water use include plant species, climate, and season. The rates for poplars and willows are the best known. The rates for other species are less known, conifers especially. The water used by an individual plant or species varies depending on the climate.

Two factors that determine the appropriateness of a particular contaminant for phytoremediation are solubility and, for a radioactive contaminant, the half-life. For instance, radioactive contaminants with long half-lives would be poor candidates for the technology due to the order of magnitude difference in the life span of trees and the difficulty in monitoring conditions across centuries. In contrast, a demonstration of a phytoremediation system at Argonne National Laboratory is evaluating the uptake of tritium (a short-lived radionuclide) by poplars and willow trees.

Phytoremediation of excess plant nutrients (nitrates, sulfates, and phosphorus) has been demonstrated at many non-DOE sites. Other contaminants that have the most promising potential for phytoremediation are chromate, barium, selenium, and strontium. Some studies have been conducted.

Handling of plants following the phytoremediation process is an important system design consideration, especially if the plant material is contaminated with heavy metals or radionuclides. The required steps will need to be determined with respect to the contaminants being addressed. Regulations may require that the plants undergo leaching tests to determine the treatment and disposal options. At the Savannah River Site, contaminated plants harvested from a radioactive waste basin required both incineration 
and disposal. The cost to concentrate, volume reduce (ashing), and bury the plants was reported to be $\$ 10,000$ per ton.

\section{$\underline{\text { Areas for Future Research }}$}

The group identified the following areas for future research:

- Root architecture in engineered (deep-rooted) systems.

- Utility of deep root aeration systems.

- Water use by established and new phytoremediation species.

- Mounding effect on a plume.

- Genetically engineered plants to increase tolerance to abiotic stress (temperature and toxics).

- Data on other species including conifers.

- Verified models with long-term data for seasonal influence on plumes.

- Cross-discipline and in-depth literature review of correlated research (agricultural, pesticide, forestry) to determine existing information on metal uptake by various plants.

- Predictive modeling of plant performance with given set of variables.

- Studies of the rhizosphere effect (the interaction between plants and microbes).

- Studies of mass-balance on greenhouse and pilot (lysimeter) scale.

- Evaluation of methods to handle contaminated plant material.

- Root turnover rates with respect to impacts of metals and climate.

- Research on root harvesting techniques.

- Examination of contaminants in natural systems, especially natural re-vegetation of waste sites.

- Plant-herbivore greenhouse studies.

- Bioaccumulation studies.

- Disturbance preparedness and mitigation.

$\underline{\text { Key Issues and Recommendations }}$

The group's ranked recommendations include:

1. Provide rigorous monitoring to verify performance at existing installations.

2. Perform literature searches on plant uptake of different contaminants and develop a "living" database.

3. Perform basic research into rhizosphere issues.

\subsection{Removal from Soil (Phytoextraction)}

Phytoextraction of inorganics is a viable remediation technology but is still developing. As with any technology, it addresses a certain suite of contaminants and conditions (it is not a "silver bullet"). Phytoextraction is effective over a wide range of time scales. Climate, contaminant, required clean up levels, and plant species are the primary 
determinants of cleanup duration. Under some conditions, as little as one to three growing seasons (years) are required to meet acceptable contaminant concentrations. Complete removal will require additional seasons and a progression of plant species/cultivars. In contrast, the removal of cesium from soil by phytoextraction may require considerably more than three growing seasons.

The group ranked key inorganic contaminants into a number of categories in order to organize and prioritize:

- Readiness - status of the technology with respect to research/commercialization.

- Uninduced phytoextraction - state of knowledge concerning plant species that concentrate the contaminant without exogenous chelating agents.

- Chelate-induced phytoextraction - state of knowledge concerning plant species that concentrate the contaminant with assistance from soil and/or plant amendments.

- Regulatory acceptance - whether the technology been approved for remediation at least one site. This does not imply widespread or general acceptance.

The ratings for each category reflect the status of research:

0 none

1 basic research underway

2 lab scale (ready for field)

3 field scale deployment

4 under commercialization

The following table is a summary of the contaminant ranking process:

\begin{tabular}{|c|c|c|c|c|c|c|c|c|c|c|c|c|}
\hline Contaminant & $\mathrm{Ni}$ & Co & $\mathrm{Se}$ & $\mathrm{Pb}$ & $\mathrm{Hg}$ & $\mathrm{Cd}$ & $\mathrm{Zn}$ & & Cs & & $\mathrm{H}^{3}$ & $\mathrm{U}$ \\
\hline Readiness & 4 & 4 & 4 & 4 & 3 & 2 & 3 & 1 & 3 & 2 & 3 & 3 \\
\hline Uninduced phytoextraction & 4 & 4 & 4 & 0 & 4 & 4 & 4 & 1 & 2 & 2 & $\mathrm{n} / \mathrm{a}$ & 0 \\
\hline Induced phytoextraction & 0 & 0 & 0 & 4 & 0 & 0 & 0 & 0 & 0 & 0 & 0 & \\
\hline Regulatory acceptance & Y & Y & $\mathrm{N}$ & Y & $\mathrm{N}$ & $\mathrm{Y}$ & $\mathrm{Y}$ & $\mathrm{N}$ & $\mathrm{Y}$ & Y & $\mathrm{Y}$ & \\
\hline
\end{tabular}

The absolute performance of phytoextraction will be limited by metal speciation and the availability of a contaminant to plants employed in the removal process. Approaches to improve plant access to contaminants are needed. Mass balance calculations are not realistic under field conditions. Typically, wide variation (both vertical and horizontal) in contaminant concentration overwhelms efforts to document mass balance. However, this difficulty does not eliminate concerns regarding mass balance, and the group was urged to consider ways to address potential leaching of metals away from the original source was well as the dilution of contamination by tillage.

\section{$\underline{\text { Areas for Future Research }}$}

The group identified the following areas for future research related to soils removal: 
- Phytoremediation speciation rates and fate of the volatilized metals with respect to metal speciation.

- Comparative risk assessment for different mercury remedial technologies.

- Screening of all radionuclides with respect to phytoextraction.

- Soil amendment studies.

- Research on selective accumulation and species screening if strontium-90 is to be treated by phytoremediation.

- Phytoextraction of uranium, which is currently being studied by MSE Technology Applications at the Fernald site (further work is needed on potential soil amendments and species screening).

- Targeted studies on the basic science of phytoremediation.

- Research and development in the area of uptake, removal, fate and transport, and effects of phytoremediation.

- Evaluation of crop rotation for enhancement of phytoremediation.

- Regulatory acceptance of phytoremediation technologies.

- Timeline for deployment of a phytoremediation technology with respect to DOE's regulatory requirements for cleanup.

- Risk to ecological receptors from contaminants in plants following uptake.

- Plant species research, including plant physiology and the possibility and need for genetic manipulation.

- Plant screening on a site with respect to contaminant levels.

- Basic research on chelators and inducement of hyperaccumulation.

- Fate of chelating agents in the soil.

- Individual site testing protocols.

- Incineration of contaminated biomass (information exists only on metal recovery).

- Life-cycle costs for phytoextraction disposal alternatives.

- Cost data on large-scale projects.

\section{$\underline{\text { Key Issues and Recommendations }}$}

The group concluded that phytoextraction technologies should be demonstrated at multiple sites and under multiple conditions. Such demonstrations would involve inherent risks of failure, and would almost certainly need to be conducted by one or more federal entities. The demonstration projects should address life-cycle cost evaluations based on both actual costs and anticipated "real world" costs. The demonstration projects should include all activities from site characterization through final disposition of contaminated biomass.

The group also recommended that total life-cycle cost accounting be developed for existing DOE (e.g., radionuclides at Argonne West and Argonne East) and non-DOE phytoextraction projects. Species screening for increased accumulation of contaminants of concern should be supported. These efforts should address those contaminants that pose the most significant risks for DOE and for which baseline remedial technologies are 
either lacking or expensive. It is suggested that such efforts focus on the radionuclides cesium and strontium.

Basic research of plant physiology and soil chemistry of inorganic compounds as it relates to contaminants of concern to DOE (e.g., selected heavy metals and radionuclides) should be supported. Finally, the issue of ecological risk should be addressed with a quantitative risk assessment based on known concentration factors and exposure periods.

\subsection{Phytostabilization/Sequestration in Soil}

Plants provide phytostabilization as a vegetative cap to control/moderate leaching, in combination with other remedial tools (chemical stabilization/phytoextraction), and as a method of erosion control. Although there is currently not enough information available for complete regulatory acceptance (in terms of cost, risk, stakeholder acceptance), stabilization/sequestration is a technology that is gaining EPA's attention as a viable remediation technology.

One issue of concern is that stabilization/sequestration efforts that result in contaminant concentrations greater than cleanup goals are not acceptable to regulators. There is a concern that because metals do not go away, all that phytoremediation is doing is shifting risk to another medium. Phytoremediation creates another route of exposure; sequestration reduces routes of exposure but bioavailability has not been investigated. However, there are several national and international demonstration sites currently investigating these issues.

The benefits and drawbacks of phytostabilization/sequestration in soil were identified, and are listed in Table 1 (see page 8).

Participants concluded that stabilization/sequestration by itself is not currently a viable option. Some of the primary concerns and risks include long-term stewardship (contaminants remain in soils), public/regulatory acceptance under specific conditions, and food chain transfer. A key problem is that sufficient data are not currently available to convince regulators that phytostabilization is viable.

\section{$\underline{\text { Areas for Future Research }}$}

Fundamental research and applied research are needed in order to create a regulatory comfort level with stabilization/sequestration. The relevant fundamental and applied research needs include:

- Study the biological uptake system as a whole in order not to lose information on synergistic effects.

- Plant/soil/contaminant matrix data are needed to determine what types of plants are applicable to stabilize specific soils and specific contaminants.

- Physiological sequestration data are needed to determine root storage and the fate of metals in the plants themselves (as opposed to adsorption). 
- Research on the bioavailability of specific contaminants and net mineralization over time.

- Research to determine tree and plant load limitations (capacity/kinetics).

- Research on ecotoxicological effects of contaminant transfer through stabilization/sequestration. Net pathway exposures.

- Research on potential to increase risks over time; research on biosolids shows that risk may increase over time (humification).

- Research on the impacts that sequestration has on the microbial population in the root zone (rhizosphere).

- Research on the effects of natural versus synthetic fertilizers.

- Research on plant selection: What is out there? What works under what conditions?

- Research on crop maintenance (e.g., how do we get crops to grow?).

- Long-term effects of chemical speciation (bioavailable vs. recalcitrant pools).

- Predictive models with realistic parameters.

- Microbial/soil/plant interactions.

- Cycling, leaching, and mobility from roots.

- Toxicity related to food chain transfer.

Table 1: Benefits and Drawbacks of Phytostabilization/Sequestration in Soil

\begin{tabular}{|c|c|}
\hline BENEFITS & DRAWBACKS \\
\hline $\begin{array}{l}\text { - Good for large areas with low concentrations of } \\
\text { - Lontaminants } \\
\text { conventional technologies } \\
\text { - Highly applicable to chromium, uranium, and } \\
\text { technetium (redox-sensitive contaminants) } \\
\text { - Effective physical method for maintaining or } \\
\text { reducing risk } \\
\text { - Good lead precipitator } \\
\text { - } \text { - Nood potential for acceptance given alternatives } \\
\text { intrusive than alternatives) } \\
\text { - Good interim measure } \\
\text { - Highly applicable in combination with other } \\
\text { technologies } \\
\text { Encourages soil improvements/conditioning } \\
\text { - Physiological applications (plants that sequester } \\
\text { contaminants in roots) } \\
\text { When removal is infeasible, integration of } \\
\text { stabilization and sequestration may be } \\
\text { appropriate }\end{array}$ & $\begin{array}{l}\text { - Little data on long-term ability to immobilize } \\
\text { contaminants } \\
\text { - Little information on bioavailability and } \\
\text { rhizosphere microflora } \\
\text { - Long-term liability/stewardship concerns } \\
\text { - Translocation/food chain transfer issues } \\
\text { (biomagnification) } \\
\text { Permanence of sequestration/stabilization may } \\
\text { become an issue when future technologies } \\
\text { become available }\end{array}$ \\
\hline
\end{tabular}


$\underline{\text { Key Issues and Recommendations }}$

Filling data gaps will not necessarily enable stabilization/sequestration to be broadly applied. Rather, stabilization/sequestration may become applicable to specific sites under certain conditions. Five areas were listed in order of highest to lowest priority and the first two are interchangeable. All agreed that they address concerns important to regulators.

Long-Term Bioavailability - The objective of this need is to identify stable forms and biogeochemical factors that impact stability as well as the effects of the rhizosphere on weathering of immobilized contaminants. This need was identified as one of the most significant data gaps. Long-term effects of metal speciation and stability, complex and chelate formation in relation to bioavailability, and humification should be considered. The studies should determine the physical and chemical interaction of minerals and the cycling behavior of contaminants. The connection between solubility and bioavailability, the differences between bioavailable and recalcitrant pools, mobility from roots via leaching and recycling, and the mechanisms of bioavailability should be considered. There was some concern about whether tasks associated with these studies would be best conducted at a particular site (thus creating site-specific information) or in a lab (potentially applicable to multiple sites). A decision was not made on this topic.

Rhizosphere Biochemistry - Research is needed to establish better methods to understand microbial, soil, and plant interactions in relation to contaminant mobilization/immobilization. It also focuses on techniques to understand contaminant transformation (enzymatic processes, chelates, etc.) from one compartment or pool to another. Technology development for ecological rhizosphere studies relative to metals and isotopes is needed. Plant and microbial relationships should be examined along with how plants and microbes influence each other's community. Clarification on metal uptake in plants is needed. A better understanding of metal partitioning in plants/microbes/soils and manipulation of the rhizosphere communities (inoculation) are also relevant.

Toxicity Related to Food Chain Transfer - An analysis is needed to compare the relative risk of contaminant bioaccumulation or biomagnification compared to no action or other technology alternatives. An ecological approach to better understand food chain transfer from trophic level to trophic level is required. Bioconcentration factors will be an important element of these investigations. Mechanisms for toxicity should be examined in a risk-based approach in order to determine impacts of metal speciation.

Physiological Sequestration in Plants - There is a need to characterize processes and examine environmental influences (such as climate, soil, and chemical) in a realistic context and apply resulting knowledge to microbial, soil, and plant interactions. Areas for study include cell wall, vacuole, exudates, transport, and root senescence and turnover. Contaminant redistribution in plants, and the impacts of plants/microbe exudates on bioavailability of rhizosphere/soil-immobilized contaminants or plant-induced chemical changes need to be addressed. 
Predictive Model - A model with realistic parameters is needed to move forward. The purpose of the model should be to estimate optimal conditions for phytostabilization and its viability for a given set of contaminant and environmental conditions. It should be a model that addresses both spatial issues (element distribution, and heterogeneities) and temporal issues (e.g., contaminant remobilization over time). It should also include "what if" scenarios, sensitivity analysis, and should address metal reactive transport and plant root influences.

These five broad research areas are not unique to the phytostabilization discussion panel. For instance, the phytoextraction group also suggested that research be conducted to better understand the complexities of the rhizosphere. However, the research outlined above is necessary in order to determine the viability of phytostabilization as a remedial action for metals and radionuclides and under what conditions could it be expected to achieve acceptable levels of risk.

\subsection{Phytoremediation Monitoring}

Phytoremediation monitoring can be divided into three categories: performance monitoring, optimization monitoring, and risk monitoring. Performance monitoring demonstrates whether phytoremediation has successfully cleaned up contaminated soil or groundwater to a predetermined standard. This is typically accomplished by measuring changes in the mass balance of contaminant concentrations in plants, soil, and/or ground water, or by measuring the plant stress response. Optimization monitoring refers to an iterative fine-tuning of the phytoremediation operation and may include monitoring and management of factors such as planting, harvesting, soil fertility, and irrigation. Risk monitoring is necessary to assure that accumulation of contaminants in plants does not cause unacceptable ecological risks.

Standard phytoremediation monitoring methods consist of ex-situ/destructive sampling of plants, soils, and groundwater and analysis in the lab. The costs of standard monitoring as the sole method may be prohibitive. Advanced methods and innovative technologies are needed to streamline monitoring, reduce uncertainty, and lower costs. Standard methods

are required, however, for calibration of advanced methods. Advanced methods and instrumentation are at various stages of development. The X-ray fluorescence (XRF) method is currently the primary analytical instrument. Hand-held XRF, chlorophyll fluorescence, and PS2 spectral reflectance methods are also currently available.

Most methods for monitoring soil phytoremediation can also be used to monitor groundwater phytoremediation. However, current measurement methods for parameters unique to groundwater such as water level, flow direction and contaminant concentration, using piezometers, are inadequate due to a mismatch of scale. Instruments based on measurement of heat flow and heat dissipation are used to measure, indirectly, 1) unsaturated flow in soils, and 2) sap flow in plants. Sap flow is measured as an indication of transpiration rate. Instruments to measure sap flow in plants are currently available, and methods that use similar instruments to measure unsaturated flow in soils 
are only a year or two from deployment. Stable isotope ratios (e.g., deuterium, oxygen) of water in plants can be used to detect if the source is from rainfall or groundwater. Tracers (e.g., bromides) are currently used to measure flow patterns in controlled experiments and are ready for field deployment. Standard groundwater analytical laboratory techniques can be adapted for field applications. Some field measurement tools are currently available.

\section{$\underline{\text { Areas for Future Research }}$}

The group determined that the following areas require additional research:

- More robust models for performance predictions.

- Sampling designs and measures of uncertainty for more advanced monitoring technologies.

- A tool for evaluating the applicability and practicality of advanced and innovative monitoring techniques that focuses on end user needs. The tool could be in the form of a decision framework consisting of a series of steps and decision points leading from site characterization, through risk assessment, to a site-specific phytoremediation design, and then to applicable performance and optimization monitoring techniques.

- Integrated test sites and field testing (e.g., SERDP) for life-cycle monitoring technologies.

- Process optimization strategies for implementation.

- Monitoring strategies to address speciation and associated effects on risk.

- How long and how often to monitor (protocols).

- Real-time data collection.

Key Issues and Recommendations

1. Sponsor field tests - DOE should sponsor well-orchestrated field tests of monitoring technologies:

- Conduct side-by-side testing of standard and innovative monitoring technologies.

- Test multiple techniques for monitoring at a single site; compare cost and performance.

- Provide opportunities for end user and regulator participation in field tests to obtain their buy-in. Explore opportunities for having a regulatory agency agree to apply an alternate cleanup standard if the field test works (like the U. S. EPA-ACAP program).

- Build on phytoremediation and monitoring work performed in Poland by field testing the Polish technologies in the U.S. (e.g., chlorophyll fluorescence).

- Look for opportunities to build integrated tool kits of monitoring instruments.

- Develop test sites that can be used to test both phytoremediation and monitoring technologies (e.g., SERDP).

2. Fund more work on using plants as characterization tools.

3. Define elements of an effective monitoring protocol: 
- Address both the instrumentation to be used and the sampling design/protocol (e.g., frequency, how long, how many samples, what scale).

- Consider both contaminant speciation and bioaccumulation.

4. Develop a common language by using the terminology "monitored phytoremediation" to indicate that phytoremediation is not a "do-nothing" option.

5. Improve coordination and communication:

- Improve coordination among DOE sites with existing or proposed phytoremediation projects.

- Conduct a workshop for technology developers and end users to devise common measurement parameters and protocols.

- Include all contaminants present at the sites (to fully account for differences in plant uptake).

- Develop a central information repository that includes a database of plant capabilities and sources of information on phytoremediation.

- Facilitate information exchange through a web site and chat room. Build on and/or include links to existing web sites designed to promote regulatory acceptance, commercialization, and evaluate cost and performance (see Appendix I).

- Consider using the Air Force Center for Environmental Excellence (AFCEE) program on natural attenuation as a model for structuring the effort and information exchange.

6. Determine why monitoring is being conducted:

- Recognize that monitoring can be conducted for a variety of purposes (e.g., research, site characterization, implementation of a remediation system, and verification), and that the methods and tools used for each purpose are different.

- Recognize that the objective of research monitoring is to reduce the parameters that need to be sampled in the field and to streamline/standardize techniques for implementation monitoring. Issues to be addressed are monitoring and measurement of root distribution, studying hyperaccumulation mechanisms, studying plant uptake mechanisms, studying how speciation affects risk in an ecosystem, and relating bioavailability to risk.

- Recognize that the objectives of implementation monitoring (monitoring during remediation) are to optimize process efficiency and save money.

7. Develop a decision framework:

- To help end users select appropriate monitoring technologies and sampling protocols.

- To ensure that monitoring is fully integrated into the decision process for a site.

- To identify site-specific technology gaps and needs. 


\subsection{LESSONS LEARNED}

The format of the phytoremediation workshop was designed to gain input from experts in order to define the status of knowledge, identify areas for future potential research, and identify recommendations and strategies for advancing phytoremediation research and application. The workshop provided tangible recommendations and met the intended objectives. Some of the reasons why the work structure worked so effectively include:

- Communication - The workshop structure was designed to enhance communication and collaboration among organizations currently involved in phytoremediation research. Experts engaged in dialogue that met this objective.

- Team Leaders - Team leaders were beneficial as they had the experience and expertise to fuel dialogue. In addition, team leaders coordinated with team members prior to the workshop. This was valuable as it resulted in a collective understanding of the process so time was not wasted explaining the process during the workshop.

- Facilitators - The workshop facilitators were of great value as they were able to keep the discussions focused and move issues forward to resolution. They also allowed team leaders to focus on discussion instead of moving the process forward.

- Note Takers - Recorders were able to track discussion items and capture important information used to develop this report.

- Pre-planning - Regular conference calls with organizers kept everyone informed and thinking about objectives and outcomes. In addition:

- Organizers with technical and organizational skill and good contacts added value to the workshop planning process.

- Developing a set of written issues before bringing organizers together resulted in better use of time.

- The invitation letter increased participation. In the future, letters should be sent to individuals instead of organizations.

- Location - Meeting rooms were located in one building, with one team per room. It was an efficient way to organize so that reconvening into smaller or larger groups was not logistically challenging.

- Duration - The duration of the workshop was short and meetings were concentrated. This resulted in efficient use of time.

- Follow-up - All the team leaders requested that their team members review the draft reports. As a result, the groups continued their discussions after the workshop, added content and details to the draft reports, and in some cases identified new issues and areas of debate. The groundwork has been laid for future collaborations. 
- Overall Recommendations - The overall recommendations should continue to be refined, clarified and focused. Now that the work of the groups is completed, a fresh look at the overall recommendations by the team leads and workshop organizers would be beneficial.

\subsection{RECOMMENDATIONS AND CONCLUSIONS}

\subsection{Key Areas of Research}

Although the four working groups developed key areas of research specifically applicable to their categories (groundwater applications, removal from soils, stabilization/sequestration, and monitoring), common themes are apparent. For example, research in the area of selective accumulation and species screening was a popular theme in all working groups. Bioavailability of specific contaminants and contaminant speciation were related areas of research that were identified by multiple groups as important. Genetic engineering of plants, improved understanding of the rhizosphere and root systems, and development of predictive models and testing protocols were also frequently identified as relevant research topics.

\subsection{Recommendations}

Recommendations from the working groups were general and had cross-applicability among working groups. The groundwater working group called for rigorous monitoring to verify performance at existing installations; literature searches on plant uptake of different contaminants; development of a "living" database; and basic research into rhizosphere issues.

Like the groundwater group, the removal from soil group called for species screening (especially for cesium and strontium) as well as basic research on plant physiology and soil chemistry of inorganic compounds. The removal from soil group also concluded that phytoextraction technologies should be demonstrated at multiple sites and under multiple conditions to address life-cycle costs (both at DOE and non-DOE phytoextraction sites) and include all activities from site characterization through final disposition of contaminated biomass. In addition, the group called for quantitative risk assessment based on known concentration factors and exposure periods.

The stabilization/sequestration group added to the recommendation for basic rhizosphere research, as presented in the groundwater group, but focused on the need to understand long-term bioavailability. The stabilization/sequestration group also suggested studies that would lead to an understanding of toxicity related to food chain transfer and physiological sequestration in plants. Finally, they recommended a predictive model with realistic parameters to define boundaries and predict the outcome of the remediation efforts.

Along with the removal from soil group, the monitoring group recommended that DOE sponsor field tests that can be used to test both phytoremediation and monitoring 
technologies. The monitoring group added specificity to the groundwater group's monitoring recommendation, as they called for specific elements to be better defined. These elements include: instrumentation to be used and the sampling design/protocol (e.g., frequency, how long, how many samples, what scale); contaminant speciation; and bioaccumulation. In addition, the monitoring group believes that "monitored phytoremediation" should be more specifically defined so it is not confused with "no action". The monitoring group also called for funding more work on using plants as characterization tools; improving coordination and communication; recognizing the breadth and depth of monitoring activities; and developing a workable decision making framework that will support end users. 
APPENDIX A

GROUNDWATER APPLICATIONS REPORT 


\section{APPENDIX A GROUNDWATER APPLICATIONS REPORT}

\subsection{OVERVIEW}

Groundwater applications for phytoremediation were defined as the use of higher plants to manage contaminated groundwater, and included the following processes: hydraulic control, contaminant removal, and sequestration. The session focused on system considerations for DOE sites. The participants included regulators, technology developers, and end users. The topics that the group identified for discussion included:

- Plant Species Selection

- Desirable characteristics

- Depth to groundwater

- Rate of water usage

- Seasonality

- Contaminants

- Appropriate target contaminants

- Fate of contaminants

- Disturbances (effects on plant and animal systems)

Discussion on each topic covered the status of current knowledge, research gaps, recommendations to resolve issues, and recommendations for future investment.

\subsection{PLANT SPECIES SELECTION}

Phytoremediation of groundwater is one of the more advanced applications of the suite of phytoremediation technologies. There are more sites installed and more past experiences in the groundwater application than in metals uptake from soil, or in degradation of organics in soil. Building on these past experiences will allow the DOE to apply the existing technologies at their sites and for their contaminants of concern, when appropriate. This section addresses the fundamental issues of plant selection for those applications.

\subsection{Desirable Characteristics}

Plants that may be used for groundwater remediation share certain physiological characteristics (many species have one or more). It would be ideal for DOE site managers and phytoremediation system designers to have a broad palette of species from which to select design elements. Desired species characteristics include:

- Tolerance for site conditions - Site-specific conditions of soil, climate, and depth to groundwater will determine the range of possible species. For example, a site with high soil salinity requires a salt tolerant plant. 
- High transpiration rate - Because plants in these application are intended to be solar powered pump and treat systems, high rates of transpiration are directly applicable to water and contaminant uptake. Generally, the higher rate of transpiration, the more useful the plant.

- Biomass - Plants with larger biomass tend to have larger capacity for water usage and contaminant absorption. Additionally, larger plants are more tolerant of stressful conditions such as drought.

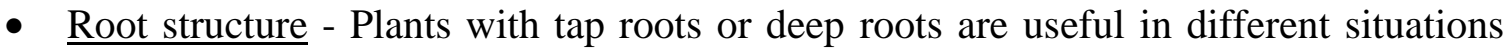
depending on soil permeability. Fibrous roots can be desirable as well.

- Uptake of contaminants of concern - In order to remove contaminants from groundwater, the plant must be capable of addressing that contaminant.

- Speed of growth - The faster a plant species grows, the quicker it can achieve phytoremediation goals.

- Restricted species - There is a general preference for the use of native (local) or noninvasive species at many sites.

- Species for ex-situ use - In addition to planting for in-situ remediation, phytoremediation can be used in conjunction with mechanical pumping. In this situation, many more species can be utilized. With an hydroponic greenhouse system (sand, pea gravel) or wetland, species selection is less restricted than in an in-situ installation.

The group identified several species that share the desirable characteristics described above. Currently most installations are using hybrid poplars and willows. Other plants suggested for different climatic regions included sagebrush, salt brush, and tamarisk. The group also identified some species such as bulrush, for example, that may have characteristics that enable them to thrive in wetlands or hydroponic conditions for the application of ex-situ treatment. Perennial shrubs, grasses, and Paulownia were all mentioned as species with desirable characteristics.

\subsection{Depth to Groundwater}

\section{Current Knowledge}

The limit of depth to groundwater for phytoremediation applications is very dependent on soil type and site conditions. Non-engineered systems, for example, are dependent on site stratigraphy. There was consensus that the 30 foot range was readily possible, and the depth limit could be extended to 50 feet with some modification.

Wetlands, greenhouses, and hydroponics can also be used to extend the possible depths for which phytoremediation can be applied. Water can be pumped up and circulated through plants in greenhouses. Another consideration when addressing depth is the mass of the selected plants roots, which declines with depth. 


\section{$\underline{\text { Research Gaps }}$}

The group discussed gaps related to aspects of root development. The first gap is an understanding of root distribution for natural and engineered systems. The second related gap is a need to understand the rate of root development. The participants also identified the need to monitor hydrological, biological, and geological conditions. For greater depths to groundwater, one approach is to plant the trees so that most of their trunks lie beneath the ground. As depth is extended, the health of the plants needs additional monitoring. For example, at the Argonne installation where some trees are "planted to their chins," trees are aerated so that the trunks stay healthy.

\section{$\underline{\text { Recommendations }}$}

From the discussion of gaps, two recommendations emerged:

- Determination of root architecture in engineered (deep rooted) systems.

- Determination of utility of deep root aeration systems.

\subsection{Rates of Water Use}

\section{$\underline{\text { Current Knowledge }}$}

Rates of water use are linked to contaminant uptake. Some of the factors known to determine rates of water use include species, climate, and season. The rates for poplars and willows are the best known, while the rates for other species are less known (conifers especially). Water use by an individual plant or species varies depending on the climate in which it is planted, and will fluctuate with precipitation. Seasonal factors are discussed in the next section (seasonality), and a literature review paper on rates is also available (Stan D. Wullshleger, Meinzer, Vertessy). Another consideration for water use is the tightness of the tree canopy. In general, a partial canopy is more effective than a full canopy because it allows greater wind passage, in turn causing greater water use. The participants concurred that modeling of water use is a useful tool for phytoremediation. The modeling work of Argonne's John Quinn was reviewed and seems to be very useful as well.

\section{$\underline{\text { Research Gaps }}$}

In the discussion concerning research gaps on the rate of water use, several topics were identified. The first was the integration of currently available data. Several participants commented that there are current phytoremediation installations and other crossdisciplinary research areas that have examined rates of water use for a variety of species. These data need to be compiled to clarify what is known and what is a gap. More data are needed on those factors that determine rates of water use in different species, clones, and varieties, as well as the impact of climate. There are additional questions about the flow velocity of groundwater and its impact on contaminant uptake effectiveness (one participant asked whether high velocity reduced contaminant uptake). Lastly, one 
participant noted that he had evidence of a mounding effect immediately surrounding the trees at an installation, while the overall effect of the installation on groundwater was a depression. There was agreement that a better understanding of what caused the mounding and its impact on the effectiveness of the installation was desirable.

\section{$\underline{\text { Recommendations }}$}

Three recommendations were identified during the discussion:

- Verification of water use by established phyto species.

- Determine water use for new candidate species.

- Explore the mounding effect on a plume.

\subsection{Seasonality}

\section{Current Knowledge}

Plants have a natural cycle of growth and dormancy that is linked to the climate. In the design of a phytoremediation system, users need to consider the site-specific conditions such as the growing season and climate, ground freezing, and the type and timing of precipitation. It is optimal to have a plant in an active state during seasons of precipitation. For example, the Hanford site in Washington State has a mismatch. During the summer (when the plants are active), there is no rain and, consequently, there is restricted groundwater and contaminant movement. Conversely, during the winter there is significant precipitation leading to increased groundwater and contaminant flow, but the plants are dormant and there is minimal contaminant uptake. The design of the planting area should be broad enough to handle the dormant period considering soil conditions and groundwater flow rate.

\section{$\underline{\text { Research Gaps }}$}

The research gaps identified focused on the benefit of identifying species with short dormancy periods. During the discussion of seasonality, several participants noted that conifers, while not being significant water users over the course of a day, are significant water users over the course of a year due to their longer period of activity. Other species that keep their leaves may have a similar advantage of being active more of the year. A warm day may be sufficient to activate a plant. Plants that shed their leaves take more time to re-grow fresh shoots, and can do so only after a period of warm weather.

Some trees have longer leaf lives than others, and thus do not need new leaves to start up the system again. The group discussed investigating ways to extend seasonality or minimize the length of the dormant period.

\section{$\underline{\text { Recommendations }}$}

There were three recommendations regarding seasonality: 
- Investigate genetically engineering plants to increase tolerance to abiotic stress (temperature and toxics).

- Gather data on other species, including conifers.

- Verify and extend currently available models with long-term data for seasonal influence on plumes with regard to phyto installations.

\subsection{CONTAMINANTS}

The discussion about contaminants centered on appropriate targets and the fates of the contaminants after their removal, and included consideration of risk and regulatory requirements. The participants had two considerations in deciding appropriate target contaminants: 1) the ease that phytoremediation can handle the contaminant, and 2) the importance of addressing the contaminant either due to its pervasiveness within the DOE complex or the associated risk factor.

\subsection{Appropriate Targets}

\section{Current Knowledge}

Two factors that determine the appropriateness of a particular contaminant for phytoremediation are its solubility, and in the case of radioactive contaminants, its halflife. For instance, radioactive contaminants with long half-lives would be poor candidates for the technology due to the relatively short life span of trees and the difficulty of monitoring conditions over hundreds of years.

The participants first considered the more highly soluble contaminants. Remediation of excess plant nutrients (nitrates, sulfates, and phosphorus) that can also be contaminants has been demonstrated at many non-DOE sites. It was reported that nitrates are a common problem across the DOE complex. Tritium, another highly soluble contaminant common at the DOE complex, has captured regulatory and stakeholder concern. A demonstration of a phytoremediation system at Argonne National Lab is evaluating the uptake of tritium by poplars and willows. A successful demonstration at Argonne could lead to installations at Brookhaven National Lab and at the Savannah River Site where there are significant tritium plumes. Additionally, many air strippers and tracer studies have already been conducted, so substantial information on the behavior of tritium already exists. Carbon-14 also has a history as a tracer and is another potential contaminant that could be addressed by phytoremediation. Its long half-life and large mass, however, complicate the design process. Other soluble contaminants that the group felt had potential for phytoremediation were chromate and barium. Among the less soluble contaminants, selenium and strontium seem to be the most promising targets, and some studies have already been conducted on them as well. There have been a series of studies in the agrochemical industry, and strontium cleanup has been tested at Chernobyl. Other contaminants worthy of mention are technetium-99, plutonium, uranium, neptunium, cesium, and cobalt-60. There was also discussion of iodine-129, but the group 
raised concerns that it would be released into the atmosphere through transpiration and could possibly result in bioaccumulation in humans.

\section{$\underline{\text { Research Gaps }}$}

There are substantial research gaps about many of the contaminants that may be appropriate targets for phytoremediation. Solubility was identified as a factor in plant uptake; however, research is needed to develop uptake modeling that will determine which contaminants are in fact the best targets. There is also a gap in knowledge on the use of additives for stabilization and the impact of additives on uptake. For example, it is known that potassium limits cesium uptake. Bioavailability must be determined based on a contaminant's physical state (colloidal versus solution, for example). Additionally there is a gap concerning the comparison between the nutrients that plants normally take up and the contaminants. The group noted that some of these gaps may have already been addressed in previous research, but that the information has not been gathered and disseminated.

\section{$\underline{\text { Recommendations }}$}

There were several references made to existing data studies and installations. One of the first steps to be taken is to develop an understanding of the existing knowledge base. Some members of the group advocated establishing a committee of experts to determine what data should be collected (mass balance, confidence, uptake, etc.). There was a general consensus that a great deal of useful data could be gathered from existing installations.

There should also be a thorough and cross-disciplinary review of correlated research (e.g. agricultural, pesticide, forestry) to determine existing information on metals uptake by various plants. Once good candidates have been identified, there should be field verification and intensive monitoring of the fate and transport of contaminants.

There should be predictive modeling for plant performance with a given set of variables. A final important recommendation was the call for studies of the rhizosphere effect, the interaction between plants and microbes.

\subsection{Fate of Contaminants}

\section{Current Knowledge}

The handling of plants following the phytoremediation process is an important system design consideration, especially if the plant material is contaminated with heavy metals or radionuclides. The required steps will be contaminant-specific. Regulations may require that the plants undergo Toxic Characteristic Leaching Procedure (TCLP) tests to determine the treatment and disposal options. At the Savannah River Site, plants harvested from a waste basin required both incineration and disposal. The cost for concentration, volume reduction (ashing), and burial was $\$ 10,000$ per ton. The 
composting of radioactive trees and woody species is a complicated option, as time, space, and radioactivity must all be considered. Contaminants may accumulate in the root, stem, and leaf, as well as at the cellular level.

\section{$\underline{\text { Research Gaps }}$}

The compilation of data on materials (e.g., toxicity) is an initial gap that should be addressed. Another issue to be addressed is the translocation of contaminants. Heavy metals and radioactive contaminants may be carried differently through the plant. Some contaminants are transported through the trunk, stem and leaves, while others remain around the roots. The biochemical process that determines translocation is not well understood. An additional gap is in the understanding of containment via water uptake versus contaminant uptake.

\section{$\underline{\text { Recommendations }}$}

The recommendation regarding fate are the following:

- Mass-balance studies on greenhouse and pilot (lysimeter) scale.

- Comparative study of rhizosphere.

- Field trials.

- Methods to handle tree waste.

- Determination of root turnover rates vis-à-vis impacts of metals and climate.

- Research on root harvesting techniques.

- Forensic ecology. Examination of contaminants in natural systems, especially natural re-vegetation of waste sites. Within the literature, there are surveys of DOE sites that should show the extent of radioactive uptake by plants.

\subsection{DISTURBANCES: EFFECTS ON PLANT AND ANIMAL SYSTEMS}

The group discussed the current knowledge of the effects of plants on animals and vice versa. Native and migratory animals may feed on and therefore damage the plants in a phytoremediation system, and may harm themselves by ingesting them. The destruction of the treatment system will result in a temporary shut down until the plants recover. In one case, a beaver visited an installation and ate 28 trees in three days, significantly reducing the effectiveness of the installation.

One advantage of the phytoremediation system is that if some trees are damaged, the remaining trees continue to function, unlike in most mechanical systems. Another advantage is that many of the trees used for phyto installations regrow if eaten or cut.

There is a possibility that an animal may die if it ingests the contaminant. In one study (Pollard, IBC 1996), insects confined with only a contaminated plant to eat died. It appeared that the insects had starved because they refused to eat the plant. 
The principal gap is in understanding the interrelationships among plants, contaminants, and animals. The recommendations are:

- Plant-herbivore greenhouse studies.

- Bioaccumulation studies.

- Disturbance preparedness and mitigation.

\subsection{KEY RECOMMENDATIONS}

Participants ranked the recommendations as follows:

- Rigorous monitoring to verify performance at existing installations.

- Literature search on plant uptake of different contaminants.

- Basic research into rhizosphere issues.

\subsection{PARTICIPANTS}

Eric Aitchenson, Ecolotree, Inc.

Robert Blundy, SRS

John Fruchter, PNNL

Edward Gatliff, ANS

Ray Hinchman, ANL-ES

Eric Lindgren, SNL

Terry McIntyre, Environment Canada

David Ow, USDA-ARA-EMSP

John Quinn, ANL-EAD

Steven Rock, US EPA-NRHRL, SITE Program

Paul Ruesche, EPA-Region 5

Neil Sturchio, ANL-ER

Stan Wullschleger, ORNL - Environmental Sciences Division

Neal Yancey, INEEL 


\section{APPENDIX B}

REMOVAL FROM SOIL REPORT 


\section{APPENDIX B \\ REMOVAL FROM SOIL REPORT}

\subsection{INTRODUCTION}

This report summarizes the discussions and recommendations of the working group on the phytoremediation of inorganic chemicals and their removal from soil. The group was assigned the general topic of "removal of inorganic contaminants from soil by plant uptake and harvesting," and was charged to address the following general topics with special emphasis on plant and soil factors:

- Current status (fundamental, applied, deployment)

- Research gaps and potential for success.

- Recommendations for future work.

The discussions took place over two days with active, productive and professional dialog. This document attempts to summarize the findings and recommendations of the group (a more detailed presentation of the group discussions is presented in Section 4.0). References are cited to support some of the points raised, though it is recognized that the listed references are not inclusive, nor are they spread consistently among all discussion topics. It was felt, however, that this was preferable to the complete exclusion of references altogether.

\subsection{FINDINGS AND RECOMMENDATIONS}

\subsection{Current Status}

Phytoextraction of inorganics is a viable remediation technology.

Phytoextraction is effective over a wide range of time scales. It can be effective under some conditions in as little as one to three growing seasons, though it will often require additional seasons and a progression of plant species/cultivars in order to meet regulatory requirements for removal of contaminants from soil. Under some conditions (e.g., removal of cesium from soil), effective phytoextraction may require considerably more than three growing seasons. Completion will phase phytoextraction into a mature plant community.

Phytoextraction is a developing and flexible technology. As such, it is applicable to a number of different contaminant and site conditions. It was agreed that with combinations of plants, methodologies, and timeframes, phytoextraction could be applicable to a variety of contaminated sites within the DOE complex. For the same reasons, phytoextraction is not yet ready for consolidation into a decision matrix or cost model. Additional experience through carefully controlled and monitored demonstrations is needed in order to obtain the necessary baseline performance and cost data.

It is not yet possible to generate a list of plant species and the contaminants to which they are best applied. The status of the technology precludes such generalizations. References can be 
found in technical literature with examples of such applications; however, site-specific conditions will continue to determine the right mix of plants and methodologies.

The group discussed nomenclature briefly. The distinction between normal plants and "hyperaccumulators" was discussed at length. The balance is between accumulation potential (mass of contaminant per unit mass of plant) and total biomass production. The discussion was divided between the chelator-induced phytoextraction plant group and the uninduced hyperaccumulator plant species groups. The former argue that high biomass crops can be induced to uptake high levels of inorganic contaminants through the use of soil chelating agents/plant amendments, while the latter argue that natural hyperaccumulation is a remarkable genetic trait which makes phytoextraction practical. There was considerable discussion regarding this distinction, however no consensus was reached. This distinction was restated as phytoextraction with plants that accumulate high concentrations of contaminants through the vegetation period without the use of soil/plant amendments, and the process that requires such amendments to boost contaminant accumulation. It was proposed that the terms "gradual accumulation" and "induced accumulation," respectively, might better distinguish those types of phytoextraction. This proposal was countered with a proposal for "selective accumulators tolerant of metals" versus "induced accumulators." The group did not reach consensus on this point of nomenclature. For the purposes of this report, these two approaches to phytoextraction will be referred to as uninduced phytoextraction and chelator-induced phytoextraction respectively.

The group discussed ecological risks associated with phytoremediation. It was agreed that there has been no documented evidence of biomagnification of contaminants as a result of phytoextraction (with the exception of selenium and methyl mercury). There are published studies of food chain studies associated with phytoextraction. These studies show that herbivores actively avoid plants with elevated levels of metals (Martens and Boyd 1994, Pollard and Baker 1997, Rosenfeld and Beath 1964). In addition, avoiding known food sources was a consideration in the original selection of phytoextracting plant species.

\subsection{Limitations}

It was agreed that there is a need to manage expectations for phytoextraction. Specifically, this includes an understanding that:

- The technology is in a "developing" stage.

- As with any technology, it addresses a certain suite of contaminants and conditions (it is not a "silver bullet").

- The time required to perform cleanup with phytoextraction will be measured in multiple growing seasons (years).

- The absolute performance of phytoextraction will be limited by metal speciation. Some fraction of a contaminant will not be available to plants under the current technology.

Mass balance calculations are not realistic under field conditions. Typically, wide variation (both vertical and horizontal) in contaminant concentration overwhelms efforts to document mass balance. However, this difficulty does not eliminate concerns regarding mass balance, and the 
group was urged to consider ways to address potential leaching of metals away from the original source as well as the dilution of contamination by tillage.

\subsection{Plant Factors}

Evaluation of indigenous species is important and should be considered in any phytoextraction activity. The use of indigenous species:

- Avoids potential problems with the introduction of exotic plants.

- Reduces the need for extensive treatability studies (the plant is already known to grow under site conditions).

Furthermore, the following considerations should be taken into account:

- Only a limited number of successful indigenous species have been identified to date.

- If non-native plant species are selected, steps should be taken to prevent their introduction beyond the remedial effort (e.g., use sterile plants or harvest before plants seed).

\section{Uninduced Phytoextraction}

By definition, uninduced phytoextraction:

- Has no need for soil chelating agents/plant amendments and associated concerns regarding contaminant migration.

- Is not available for some contaminants (e.g., lead, cadmium).

- Provides continuous uptake and contaminants are present in the plant during the entire growth cycle.

- May be balanced by evidence for avoidance of metal-contaminated plants by herbivores and insects (this will need to be documented).

\section{Chelate-Induced Phytoextraction}

In contrast, induced phytoextraction:

- Requires soil/plant amendments.

- May have potential risks associated with amendment application (multiple doses over multiple years).

- Has no evidence to date of adverse ecological impacts from use of amendments.

- Has limited evidence regarding ecological impacts from use of amendments. Initial studies of impacts to soil microbial communities in Poland shows no adverse effects from Ethylenediaminetetraacetic Acid (EDTA) application (Galiulin, Baskin et al. 1998).

- Limits exposure by very short-term concentration of contaminants in plants.

- Provides applicability where none exists otherwise. 
- Improves plant performance through:

- Increased understanding of physiology (plant, rhizosphere) as it relates to phytoextraction (e.g., uninduced phytoextraction).

- Screening of species/ cultivars.

- Selective breeding.

- Genetic modification.

\subsection{Contaminant Factors}

\section{$\underline{\text { Metals }}$}

Application of phytoextraction to some inorganics is "ready for prime time" (e.g., nickel, cobalt, cadmium, selenium).

There are concerns about the cost and ecological impacts of the phytoextraction of lead. The Remediation Technologies Development Forum's (RTDF) In Situ Inactivation and Natural Ecosystem Restoration Technology Group (IINERT) will produce results from a lead study. This group is developing documentation of processes to inactivate lead. This addresses issues associated with ecosystem protection from silver mine waste (zinc, lead, and cadmium).

There are concerns regarding efforts to volatilize soil mercury. Translocating mercury from one medium to another does not solve the initial problem. The technology is promising, but final disposition of the target metal and regulatory acceptance were seen as a major issues.

More information is needed on speciation, including the geochemistry and bioavailability of key inorganic species.

\section{$\underline{\text { Radionuclides }}$}

Low concentrations of cesium represent significant toxicity and thus present a good target for phytoremediation. There are plants (Amaranthus, Kochia) that will preferentially take up cesium in the presence of potassium. However, there has been no additional screening for higher performing strains within the genera (search for genetic diversity). There is a possibility for significant improvements in performance at a relatively low cost by screening these plants.

Cesium is generally bound tightly to soil particles (60-90 percent bound). This is due to the movement of cesium to within the layers of expanding clays, which removes cesium from the labile pool of cesium and potassium in soils. Present plant models take up one to four times soil concentration. This leads to comparatively slow remediation, but is effective nonetheless. It is estimated that phytoremediation can reduce the active half-life of cesium contamination in soils by 50 percent. Results reported by Lasat et al. indicate that cesium bound to micaceous clays in aged soil (not recently contaminated) is very difficult to remove, and there may be a recalcitrant fraction that is not bioavailable, even with soil amendments. It was noted that it may be difficult to achieve cleanup goals for cesium in aged soil and that there is a need to conduct more research to improve the bioavailability of cesium for plant uptake. Some DOE research on cesium and phytoextraction is underway (Argonne West, Brookhaven). 
Preliminary results show that plants readily uptake strontium, move it to the leaves, and can remove as much as 20 percent in one crop. These results encourage more research for phytoextraction of strontium. Calcium competes for uptake, and there is a need for further plant research.

Uranium poses a problem as both a radionuclide and toxic heavy metal. Field-scale deployments have been conducted at Fernald and some research has been conducted at Ashtabula (Phytotech) for phytoextraction of uranium. This is seen as a promising area of application for phytoextraction. The low solubility of uranium will require chelators or novel hyperaccumulating plant species. Work to date has involved mobilization with citric acid, which is seen as a comparatively "friendly" soil amendment because it is relatively cheap and biodegrades rapidly. Depleted uranium munitions are a cleanup problem for DoD, and thus present an opportunity for interagency cooperative research.

To date, plant work with tritium has involved uptake and volatilization. Tritium is not seen as a candidate for phytoextraction in the same sense as the other inorganic compounds considered, therefore the group did not address tritium as such.

Most other radionuclides are both chemically and toxicologically challenging and do not yet have phytoextraction solutions under development. Cesium is the exception to this generalization, as the phytoextraction of cesium is a promising area and should be supported by DOE.

\subsection{Induced Accumulation}

Insoluble contaminants require chelating agents. Methodologies for chelator-induced phytoextraction exist for lead. Information is needed on:

- Lead mechanisms in soil (speciation, mobility).

- Ecological impacts of phytoextraction process.

Research is needed on other insoluble inorganic compounds (uranium, for example). Concerns exist regarding the mobility of radionuclides or other inorganic components in the presence of chelating agents.

\subsection{Disposal}

There are limited data and experience with the disposal of contaminated crops. Costs will be sitespecific (proximity to treatment facility, nature of the waste (e.g., hazardous versus mixed), and final disposal requirements). Transportation can drive up the costs of remediation technology.

Incineration/pyrolysis are promising options. The resulting ash will require stabilization and disposal, however this was considered a positive factor. If the biomass is placed in a landfill, anaerobic biodegradation could cause solubilization of the contaminant and promote leaching. 
The ashing/stabilization allows a compact and more chemically stable form of the contaminant (e.g., radionuclide) to be disposed.

Portable treatment units need to be acquired and permitted.

\subsection{Costs}

Costs will be site-specific and will be difficult to estimate until significant "real world" work has been completed. Initial demonstrations will be expensive (over-engineered, over-monitored, special regulatory concerns). These costs should rapidly decline as experience increases; however, actual costs may be two to ten times the actual remediation effort when considering the permitting process and "overhead" associated with work at federal facilities.

\subsection{Recommendations}

1. The phytoextraction technology should be demonstrated in multiple sites and under multiple conditions. It was agreed that such demonstrations would involve inherent risks of failure. Consequently, it is likely that regulators would require the development and guarantee of implementation of contingency plans. Therefore, such demonstration projects would almost certainly need to be conducted by one or more federal entities. The demonstration projects should address a life-cycle cost evaluation, based on both actual costs and anticipated "real world" costs (excluding those that are unique to a first-run demonstration by DOE). The demonstration projects should include all activities from site characterization through final disposition of contaminated biomass and should use the standard testing and analytical procedures and protocols accepted by EPA and state regulatory agencies to verify the performance of phytoremediation in the field.

2. Total life cycle cost accounting for existing phytoextraction projects (DOE and elsewhere) should be developed. These could include ongoing projects with radionuclides at Argonne West and Argonne East.

3. Support species screening for increased accumulation of contaminants of concern. These efforts should address those contaminants that pose the most significant risks for DOE and for which baseline remedial technologies are either lacking or expensive. It is suggested that such efforts focus on the radionuclides cesium and strontium.

4. Support basic research of plant physiology and soil chemistry of inorganic compounds as it relates to contaminants of concern to DOE (e.g., selected heavy metals and radionuclides). Advances in these areas could greatly improve the performance and safety of phytoextraction for DOE.

5. Address the issue of ecological risk with a quantitative risk assessment based on known concentration factors and exposure periods (compare to appropriate benchmark values). This should be included as a part of the recommended demonstration. 
In its final meeting, the group was asked to rank a series of important inorganic contaminants for "readiness" in a number of areas.

The group ranked key inorganic contaminants into a number of categories:

- Readiness - status of the technology with respect to research/commercialization

- Uninduced phytoextraction - state of knowledge concerning plant species that concentrate the contaminant without exogenous chelators.

- Induced phytoextraction - state of knowledge concerning plant species that concentrate the contaminant with assistance from soil and/or plant amendments.

- Regulatory acceptance - has the technology been approved for at least one site for use as a remedial technology. This does not imply widespread or general acceptance.

The ratings for each category reflect the status of research:

$0=$ none

$1=$ basic research underway

$2=$ lab scale (ready for field)

3 = field scale deployment

$4=$ under commercialization

\begin{tabular}{|l|l|l|l|l|l|l|l|l|l|l|l|l|}
\hline \multicolumn{1}{|c}{ Contaminant } & $\mathrm{Ni}$ & $\mathrm{Co}$ & $\mathrm{Se}$ & $\mathrm{Pb}$ & $\mathrm{Hg}$ & $\mathrm{Cd}$ & $\mathrm{Zn}$ & $\mathrm{As}$ & $\mathrm{Cs}$ & $\mathrm{Sr}$ & $\mathrm{H}^{3}$ & $\mathrm{U}$ \\
Category & & & & & & & & & & & & \\
\hline Readiness & 4 & 4 & 4 & 4 & 3 & 2 & 3 & 1 & 3 & 2 & 3 & 3 \\
\hline Uninduced phytoextraction & 4 & 4 & 4 & 0 & 4 & 4 & 4 & 1 & 2 & 2 & $\mathrm{n} / \mathrm{a}$ & 0 \\
\hline Induced phytoextraction & 0 & 0 & 0 & 4 & 0 & 0 & 0 & 0 & 0 & 0 & 0 & 3 \\
\hline Regulatory acceptance & $\mathrm{Y}$ & $\mathrm{Y}$ & $\mathrm{N}$ & $\mathrm{Y}$ & $\mathrm{N}$ & $\mathrm{Y}$ & $\mathrm{Y}$ & $\mathrm{N}$ & $\mathrm{Y}$ & $\mathrm{Y}$ & $\mathrm{Y}$ & $\mathrm{N}$ \\
\hline
\end{tabular}

\subsection{PARTICIPANTS}

Mike Kuperberg, Florida State University (Team Lead)

Gary Banuelos, USDA

Rufus Chaney, USDA

Michael Coia, ART, Inc.

Slavik Dushenkov, Rutgers University

Greg Hulet, INEEL

Michael Krstich, EMS
Rafal Kucharski, IETU, Poland

Mitch Lasat, USDA

Scott Lee, ANL-W

Yin-Ming Li, Viridian Environmental

Keith Rose, EPA

Norman Terry, U.C. - Berkeley

Amy Grotefendt, EnviroIssues (Facilitator)

Mary Fitzpatrick, ANL (Recorder) 


\subsection{DISCUSSIONS SUMMARY}

\subsection{Ongoing Demonstrations}

Participants discussed current sites where phytoextraction is being used. The following examples were cited:

- At Argonne National Laboratory-West (ANL-West), phytoextraction is being used to remediate cesium-137. The use of the Kochia plant has completed its first season following a bench-scale test, and both the plant and root will be harvested over the one-half acre site. The targets appear to have been reached following this first growing season.

- Another site at ANL-West is using phytoextraction to treat multiple inorganics (zinc, mercury, silver, and selenium). Willows are being used for the two-year demonstration, which has completed its first year and is awaiting test results. The inorganics are being sequestered in the roots over the one-half acre site.

- At ANL-East, phytoextraction is being used to remove tritium and volatile organic carbon (VOC) compounds from groundwater. This is being accomplished using hybrid poplar. The trees were planted in the summer of 1999.

- At Brookhaven National Laboratory (BNL), a three-year CRADA is being implemented at a wetland-based cleanup where cesium, zinc, mercury, silver, and chromium are being remediated. A plant list for use in remediation is being developed and genetically engineered plants will be used for mercury volatilization.

- At the Portsmouth site in Ohio, willows have been planted to serve as a barrier for existing plumes.

- "Phyto-mining" of nickel is currently being tested in several areas. Phytoextraction as a commercial alternative for strip mining is being tested at commercial scale in two locations in the U.S., and some testing is taking place in South Africa and Albania.

- In the Ukraine, plants are being used to remove radionuclides from soil. Amaranthus, Cannabis, Brassica and other plant species were tested in phytoextraction field studies for cesium-137 removal. The potential role of phytoextraction in radionuclide-contaminated land risk management is being studied in the Chernobyl Exclusion Zone.

- The U.S. Department of Agriculture (USDA) is currently focusing on inorganics that have resulted from mining operations, including zinc, cadmium, cobalt, and nickel. Treatment of zinc and cadmium using phytoextraction is currently in the feasibility study stage, and cobalt60 is ready for full-scale implementation but requires funding.

- Selenium extraction using phytoextraction is being implemented on twenty acres in California and is in its third year. The preliminary results have seen a fifty to sixty percent removal of soluble selenium. After harvesting, the plants are being baled and sold for use in feed pellets (food and animal studies are being conducted currently). Crop rotation and farmer and public acceptance are issues being addressed. 


\subsection{Contaminant Factors}

\section{Mercury}

\section{Current State}

Mercury uptake and subsequent volatilization by plants are currently being used in wetland areas in New Jersey. Mercury has been found to accumulate in root tissue in sediments. Regulators in both Oak Ridge and New Jersey, however, have raised concerns about the process. It was agreed that this approach will need further discussion prior to widespread acceptance. Mercury in the form of $\mathrm{Hg}^{0}$ is being released through the volatilization process.

Gaps

- Mercury speciation is an important topic for further discussion.

- There is a need for additional dialogue on the use of volatilization as a remedial approach for mercury before both regulators and the public will accept it.

- Sound scientific data are needed on alteration rates and fate of the volatilized metal.

- A comparative risk assessment for different mercury remedial technologies is needed.

\section{$\underline{\text { Selenium }}$}

\section{Current State}

Selenium volatilization is possible but not widely accepted, though it has proven to be a good example of the successful application of phytoextraction technologies. Field scale research activities currently underway are producing a selenium-containing plant crop that can be sold as an animal feed supplement. The important role of sulfate competition with selenate accumulation was discussed. High sulfate in these soil/irrigation waters required that phytoextraction/phytovolatilization be conducted in the field, as sulfate is even more concentrated in drainage water or evaporation ponds. Speciation is very important when considering phytoextraction for selenium contamination. Biomagnification has only been observed in aquatic systems and is not considered a problem for terrestrial applications of phytoextraction of selenium.

\section{$\underline{\text { Lead }}$}

\section{Current State}

Lead is not a phytoavailable contaminant and therefore requires the use of chelators (e.g., EDTA) to mobilize the metal in the soil. Soil amendments are added in the field, resulting in uptake and plant death within one week. Perceived risks to the environment have lead to ex-situ treatment in some instances (firing ranges, for example). A DOE-funded demonstration project in Poland is collecting information on the full-scale costs and efficiency of phytoextraction using commercially available (agricultural) technologies. Contaminants being treated include lead, zinc, and cadmium. Soil amendments (EDTA) account for approximately seventy percent of the remediation costs in Poland. Efforts are underway to reduce this portion of the cost. 


\section{$\underline{\text { Nickel/Cobalt }}$}

\section{Current State}

These two compounds are felt to be the furthest along in terms of deployment of phytoextraction. Both metals are preferentially accumulated by specific plant species without the use of chelating agents. Phytoextraction for both metals is in the process of commercialization and has achieved regulatory acceptance.

\section{$\underline{\text { Radionuclides }}$}

\section{Current State}

Cesium, strontium-90, and uranium are all radionuclides where some knowledge about their phytoremediation potential is known. When looking at radionuclides, it is important to look at both radioactivity and concentration. The current state of cesium remediation has found Amaranth to be a potential accumulator. There are potential solutions for cesium uptake, but more funding and research is needed. Cesium is in the most advanced stage of research of all of the radionuclides. The most studied form is cesium-137, which is bound heavily to the soil in clay materials. Currently there is a three-year wetlands uptake study (Fuhrman) which is addressing cesium uptake, and ongoing projects in Europe are addressing cesium behavior. Uranium can be solubilized in soil and may be a candidate for phytoremediation. Phytoextraction of technetium is possible, however it is limited by sulfate competition. Plants evaluated to date have been intolerant of technetium in shoots. A potential exists for application of phytoextraction to technetium if the need warrants an investment in research.

Gaps

- The ability to use phytoremediation for other radionuclides is unknown and less probable due to their characteristic insolubility.

- A screening of all radionuclides with respect to phytoextraction is needed.

- There is a need for a soil amendment (there has been no implementation in the field to date).

- Further research is needed on selective accumulation of strontium (it is inhibited by calcium) and species screening if strontium is to be treated by phytoremediation.

- Further research is needed on selective accumulation of cesium (it is inhibited by potassium) and species screening if cesium is to be treated by phytoremediation.

- Phytoextraction of uranium is currently being studied by MSE Technology Applications at Fernald, but further work is needed on potential soil amendments and species screening.

\subsection{Basic Science Needs}

\section{Current State}

Our understanding of the basic science of phytoremediation varies widely by contaminant and by plant species. Some aspects of this technology are well understood, while many others are the subjects of intense debate. 
$\underline{\text { Gaps }}$

- Directed, targeted studies on the basic science of phytoremediation are needed.

- Research and development are needed in many of the basic areas associated with phytoextraction (e.g., uptake, fate and transport of contaminants in the presence of chelating agents, disposal of contaminated crops).

- More information is needed in the area of crop rotation.

\subsection{Implementation}

\section{Current State}

It will be important to manage the expectations of end users and regulators regarding phytoextraction. Phytoextraction is a tool that can be used to remove some inorganic contaminants from soils under particular conditions. It is not a "one size fits all" technology. It will be important to educate potential customers to the fact that phytoextraction, like any other technology, will need to be evaluated and applied on a site-by-site and species-by-species basis. It was emphasized that phytoextraction is in the developmental stage, is a very flexible technology, and has been shown to meet a diverse set of needs.

\section{$\underline{\text { Gaps }}$}

- There are no existing testing protocols for determining whether phytoremediation will be successful at a specific site.

- There is a need to demonstrate this technology at experimental sites before it will be broadly accepted or deployed.

\subsection{Regulatory Acceptance}

\section{Current State}

Regulators are generally looking for a scientifically defensible basis for performance expectations. Results of bench-scale or greenhouse tests using site-specific soils are compelling evidence for predicting performance. It is also important to be realistic about the amount of time required for cleanup, acknowledging where phytoremediation is being used as a long-term remediation approach. For long-term remediation, the cost-effectiveness of the approach may be a factor. In addition, it will be important to show the controls in place to protect both ecological and human receptors. The fate of the contaminants (e.g., mercury and the volatilization processes) should also be predicted. Regulators will be looking for contingency plans in case of failure of the proposed phytoremediation technology and the willingness of the end user to implement that alternate technology. It was suggested that we confirm predicted performance by conducting one to two year field studies. Such studies should be prepared to implement contingency remedies if field performance is inadequate to achieve cleanup goals in a reasonable timeframe. The potential for adverse impacts to ecological receptors should be addressed by 
conducting a screening risk assessment and by comparing predicted exposures to reference values in the literature.

$\underline{\text { Gaps }}$

- Regulatory acceptance of phytoremediation technologies is a critical gap.

- Meeting risk-based limits may require measures to limit exposure in addition to removing contamination.

- It is not known whether the timeline for deployment of a phytoremediation technology matches DOE's regulatory requirements for cleanup.

\subsection{Phytoremediation Treatment Approaches}

Some participants suggested that phytoremediation technologies be separated into two categories: short-term and long-term. Active phytoextraction may be more appropriate for a short-term remediation approach (one to three years) while other phytoremediation technologies may be used for long-term risk reduction through passive processes. Other participants felt that attempts to make this distinction were arbitrary and might result in fragmentation of the technology. Phytoremediation could be seen as a long-term process with some short-term mechanisms that can be applied to address risk more quickly.

\subsection{Safety - Ecological and Human Health Risks}

\section{Current State}

There is a need to document potential risks (or lack thereof) to humans associated with phytoremediation. Specific pathways of concern and appropriate engineering controls to prevent risks to human health during phytoremediation should be defined.

Current approaches to managing risks to ecological receptors include growing plants that are not generally consumed or do not biomagnify the contaminants, or instituting engineering controls. Some plants with high concentrations of metals have been reported to be avoided by herbivores. Potential metal concentrations in plants need to be calculated and quantitative ecological risk assessments conducted to determine if ecological receptors could be exposed to metal concentrations exceeding the appropriate reference values.

The potential leaching of radionuclides following the addition of chelators was a point of concern. It was pointed out that routine application of zinc-chelate fertilizers can mobilize contaminants or radionuclides (as documented in papers by Arthur Wallace et al.).

There is also a known risk of using plants that may be noxious weeds or non-native species. Current approaches include harvesting before seeds are produced, using sterile plants, and using plants that do not flower. Such risk factors must be taken into account when selecting a plant species. 
$\underline{\text { Gaps }}$

- There is not a clear understanding of the risk to ecological receptors from contaminants in plants following uptake.

- There is not a clear understanding of the baseline risk posed to ecological receptors from phytoremediation technologies.

\subsection{Plant Improvement}

\section{Current State}

Genetic engineering may be an attractive solution to addressing limitations in available plant species, even if multiple years are required to address the problem. It is important to recognize that there are various levels of plant improvements, ranging from species screening to genetic engineering. Based on need and the length of time available there may be several options for plant improvements, including solutions within the next 3 to 5 years.

\section{$\underline{\text { Gaps }}$}

- Adequate funding is not currently available.

- There is a need for further plant species research, particularly regarding plant physiology and the possibilities for genetic manipulation.

- There is a need for plant-specific screening based on site and contaminant levels (as opposed to open-ended research).

\subsection{Uninduced Phytoextraction}

\section{Current State}

Plant species capable of accumulating contaminants without the use of exogenous chelators (hyperaccumulators) currently exist for zinc, cobalt, selenium, nickel, and manganese (one accumulator of arsenic has been reported). Chelator-induced phytoextraction of lead has been established and is available.

\section{$\underline{\text { Gaps }}$}

- Lead and uranium removal cannot be accomplished without the use of chelating agents.

- Root exudates may aid phytoextraction, but there is not a clean understanding of how this effect is achieved.

- There is a need for basic research on chelators and inducement of hyperaccumulation.

- The fate of chelators in the soil should be documented. 


\subsection{Soil}

\section{$\underline{\text { Current State }}$}

The current regulatory approach to soil contamination varies by contaminant. For example, the acceptable concentration of chromium in soil depends on its chemical form. It is possible to reduce $\mathrm{Cr}(\mathrm{VI})$ to $\mathrm{Cr}(\mathrm{III})$, which precipitates as a less toxic form. Lead speciation in soil, however, is not generally considered in the development of cleanup goals. A number of physical/chemical factors influence of the bioavailability of common soil contaminants. Proposed remedial technologies may alter the balance of those factors. A more thorough understanding of these processes is necessary.

$\underline{\text { Gaps }}$

- Some entities are looking at chemical interactions that promote success in uptake, but these results have not yet been published.

- Individual site characterization remains critical.

- Mobilization remains a concern due to the introduction of chelating agents.

- Speciation of inorganic contaminants and selective uptake of different species should be considered when evaluating the effectiveness of phytoextraction.

\subsection{Disposal}

\section{Current State}

Disposal was seen as an area of critical importance. The lack of large-scale demonstration projects has hindered the gathering of cost and performance data for disposal options. Some contaminants (selenium and zinc, for example) may be phytoextracted and then sold as biomass to animal feed markets, thus recovering some of the remediation costs. Other contaminants (e.g., nickel, cadmium, cobalt) may be "phyto-mined," recovered in biomass ash, and marketed as metals. Sites with combined contamination will be problematic since uptake is not selective (at least between cadmium and zinc). DOE currently has some renewable energy labs, which may have use for biomass created by phytoextraction. Existing DOE incinerators do not provide for energy recovery and do not burn radionuclide-contaminated biomass or, in most cases, take offsite waste. There are, however, some incinerators in Europe that burn highly concentrated radionuclide biomass, enabling the biomass to be harvested as hay and baled for burning. The disposal method currently used by the majority of phytoremediation projects is incineration due to the volume reduction achieved. Dioxin/furan creation remains an issue at some incinerators. Permitted portable facilities are seen by some as an important option for addressing phytoextraction disposal needs. Pyrolysis has been looked at in a few instances as a disposal alternative and may be an option, but will require additional research.

\section{Gaps}

- There is little or no pilot data on incineration of contaminated biomass; information exists only on metal recovery. 
- Generally, there are little or no lifecycle cost data available for phytoextraction disposal alternatives.

\subsection{Costs}

\section{Current State}

Currently, costs for phytoremediation are known on a site- and technology-specific basis. Generally, project tasks such as administration, design and other regulatory processes account for ninety percent of the project cost, while the actual plantings and maintenance account for the remainder. At some sites permitting has accounted for a doubling of the costs, and performance assessments can dramatically increase the funding required. Costs for planting a crop generally range from $\$ 60$ to $\$ 100$ per acre for annual seed crops (e.g., corn or wheat). Forage crops (alfalfa, for example) which must be repeatedly cut and made into hay will have higher production costs. Monitoring costs are also an important consideration.

$\underline{\text { Gaps }}$

- "Standard" costs are not yet available for phytoremediation technologies. Such information should be collected as part of proposed large-scale demonstrations.

- There are no known cost data on large-scale phytoextraction projects.

- Data on plant accumulation of elements are available, but these studies were not managed phytoextraction tests from which accurate costs could be obtained.

\subsection{Mass Balance}

\section{Current State}

The group agreed that mass balance is a laudable goal for documenting the effectiveness of phytoextraction; however, it has not yet been accomplished under existing field conditions. The heterogeneous nature of most sites makes determining a mass balance difficult. Following remediation, it is necessary to demonstrate that no leaching or migration occurred, however, it is nearly impossible to use mass balance to show that result at field sites. The current approach is to test the soil for remaining contamination in order to determine whether the site can be closed. Another potential approach is to extrapolate the results from greenhouse tests to the field, picking predictors in the field for verification. Speciation should also be considered when determining the extent of remaining contamination (i.e., what form the remaining contamination is in, what risks are associated with it, its overall stability). There are questions as to whether chelator-induced phytoextraction of lead will result in final concentrations that are acceptable to regulators. The nature and concentration of the remaining contamination and the regulatory view of that remainder may determine the success of phytoextraction. 


\section{APPENDIX C STABILIZATION/SEQUESTRATION IN SOIL REPORT}




\section{APPENDIX C STABILIZATION/SEQUESTRATION IN SOIL REPORT}

\subsection{INTRODUCTION}

To date, most of the development efforts surrounding phytoremediation as a remediation technology for inorganic contaminants (particularly heavy metals and radionuclides) have centered on removal from soils and water via plant accumulation. Inherent with this concept is the implicit assumption that for those systems that accumulate metals, plant residue removal is integral to the technology. Phytoremediation technology, however, may be subdivided into three categories or subsets: phytoextraction - the use of plants to remove toxic metals from soils; rhizofiltration - the use of plants to remove toxic metals from polluted waters (Dushenkov et al. 1997); and phytostabilization - the use of plants to eliminate the bioavailability of toxic metals in soils (Salt et al. 1995; Wenzel et al. 1999). Phytoextraction is the topic of its own panel discussion in this workshop (see Appendix B). Phytostabilization is synonymous with sequestration and stabilization and was the focus of this workshop panel. Phytostabilization may be broadly considered to be the use of plants for the reduction of contaminant bioavailability and risk (human health and environmental health) that incorporates both physical and biogeochemical processes without removal and disposal of plant residue.

As a physical management technology, plants have been utilized in revegetation of barren lands to minimize erosion by wind and water and as a hydrologic control to reduce leaching. Biogeochemical phytostabilization is more difficult to define succinctly, but incorporates the isolation of contaminants from the soil solution and hydrological process through plant uptake (largely in root biomass) and/or plant/rhizosphere-induced immobilization. The latter should be effective in sequestering redox sensitive inorganic contaminants (e.g., $\mathrm{Cr}, \mathrm{U}$, and Tc) by the reduction of the highly mobile species [Cr(VI), U(VI), and Tc(VII)] to the insoluble, immobile [Cr(III), U(IV), and Tc(IV)] species as a result of plant-rhizosphere interactions. Additionally, it is assumed that contamination must be shallow, within 1-2 meters of the surface, to foster significant plant root exploration/coverage of the contaminated soil.

The agenda of the stabilization/sequestration panel focused on current viability of phytostabilization (i.e., the current state of knowledge), identifying the benefits and drawbacks of phytostabilization, identifying information gaps, prioritizing information gaps, and making recommendations regarding phytostabilization.

\subsection{CURRENT STATUS}

Discussion of phytostabilization as a viable remedial technology for soils contaminated with metals and radionuclides centered on three major issues. First, toxic metals cannot be destroyed; hence, they are subject to environmental changes (chemical, physical and biological) that could, over time remobilize the metal contaminants. While radionuclides ultimately decay, longer-lived isotopes (half-life greater than 7 years; e.g., cesium-137 or strontium-90) persist for many years since 10 half-lives are normally required before the nuclide is considered to have decayed away. Hence, radioactive decay (or natural attenuation) may not make phytostabilization any more or less attractive for radionuclides than for heavy metals. The second issue is regulatory acceptance. Currently, there does not appear to be enough information (in terms of cost, longevity, and risk), 
for most scenarios, for current regulatory and stakeholder acceptance. Third, is the issue of use, consideration of where phytostabilization would be used as opposed to phytoextraction or other existing technologies.

Stabilization of soils against erosion via the use of cover crops is well known and utilized in agriculture and civil engineering applications. Remobilization of sediment-associated uranium (U) from contaminated floodplains sediments during rain events has been documented at SRS (Batson et al., 1996). During the floodplains study it was demonstrated that up to 1500 to $2800 \%$ more $U$ was exported to an adjacent stream system during storm events due to erosional processes. Phytostabilization of these sediments could reduce this $U$ transport by controlling erosion. There are several studies currently investigating the use of phytostabilization for erosion control of metal contaminated soils. A study in the UK investigated the use of metal-tolerant plant species to revegetate heavy-metal contaminated soils (Smith and Bradshaw, 1979). The intent here was the control of erosion (wind and water). Utilization of metal-tolerant plant species is also being investigated to stabilize cadmium and zinc contaminated soils in Palmerton, PA (Rufus Chaney, personal communications as reported by Salt et al. 1995). At a site in Joplin, MO, tall fescue is being considered as an erosion control tool to minimize transport of lead oxide from smelter fallout. Other projects, discussed in an anecdotal or thumbnail sketch manner, are summarized below.

- Near Seville, Spain, a dam breach at a mining site has contaminated soils over a wide area with lead, arsenic, and zinc and other metals. Phytoremediation (both extraction and stabilization) may be the best option to clean up the metals from that accident.

- International Organic Solution (IOS) (a private corporation) is utilizing redwood trees as a curtain to intercept organic and inorganic contaminants leached from a landfill in the city of Santa Rosa, CA.

- Past practices and operations of the Anaconda Smelter, a Superfund site in EPA Region 8 have contaminated soils with $\mathrm{As}, \mathrm{Cd}, \mathrm{Cu}, \mathrm{Pb}$, and $\mathrm{Zn}$. Phytostabilization (using metal tolerant plants) in conjunction with chemical stabilization (adding lime/limestone to adjust $\mathrm{pH}$ as well as organic material and phosphorous) is being employed. The Reclamation Research Unit at Montana State University is conducting the work (Neuman et al. 1996).

- Past mining and mineral processing operations at the Big River Mine Tailings Superfund Site in Region 7 have released $\mathrm{Pb}$ (and $\mathrm{Cd}, \mathrm{Zn}$ ) into the environment, resulting in elevated blood lead levels in children as well as elevated $\mathrm{Pb}$ levels in fish tissues acquired adjacent to the site. The mine waste and mill tailings surface will be stabilized via application of organic amendments (e.g., compost) and establishment of a vegetative cover. MSE Technology Applications is performing this demonstration under EPA's Mine Waste Technology Program (MSE, 1999)

- Lead stabilization is being employed as part of a three-year RCRA corrective action. The project is focusing on chemical stabilization and plant growth. They are in their second year.

Many of the above sites are using phytostabilization as erosion control or in combination with other technologies (e.g., chemical immobilization, phytoextraction) to reduce risk. Whether the intent of the stabilization is erosion control or to explicitly immobilize metals/radionuclides 
through plant uptake or other biogeochemical processes, the plant species utilized require certain attributes. Clearly, they must be metal tolerant species, but if biomass removal is not part of the remedial process then translocation to shoots needs to be minimized to limit the potential for food chain transfer. Also, the plant species utilized must not increase the potential for leaching of metals and radionuclides over time. Phytoextraction of transuranic elements has occurred at the Savannah River Site (SRS) where plant roots have penetrated unlined low-level waste containing earthen trenches (Murphy and Tuckfield, 1994). Two major pathways by which plants could increase metal leaching are through 1) the production of organic acid root exudates that complex metals and change the metals mobility, and 2) the production of contaminated detritus that, through microbial degradation and transformation, may increase metal mobility.

Panel participants concluded that, while phytostabilization for erosion control may be reasonable for very specific conditions, phytostabilization by itself is not currently a viable option as an insitu immobilization strategy. Some of the primary concerns and risks (see below) include longterm stewardship (contaminants remain in soils), public/regulatory acceptance under specific conditions, and food chain transfer. A key problem is that sufficient data are not available to convince regulators that phytostabilization is viable. However, it was agreed that phytostabilization does have the potential to be a valuable remedial action tool in the future. The benefits and drawbacks of this type of remediation, as a stand-alone technology or in combination with other technologies, are listed below:

Table C-1: Potential Benefits and Drawbacks of Phytostabilization

\begin{tabular}{|c|c|}
\hline BENEFITS & DRAWBACKS \\
\hline 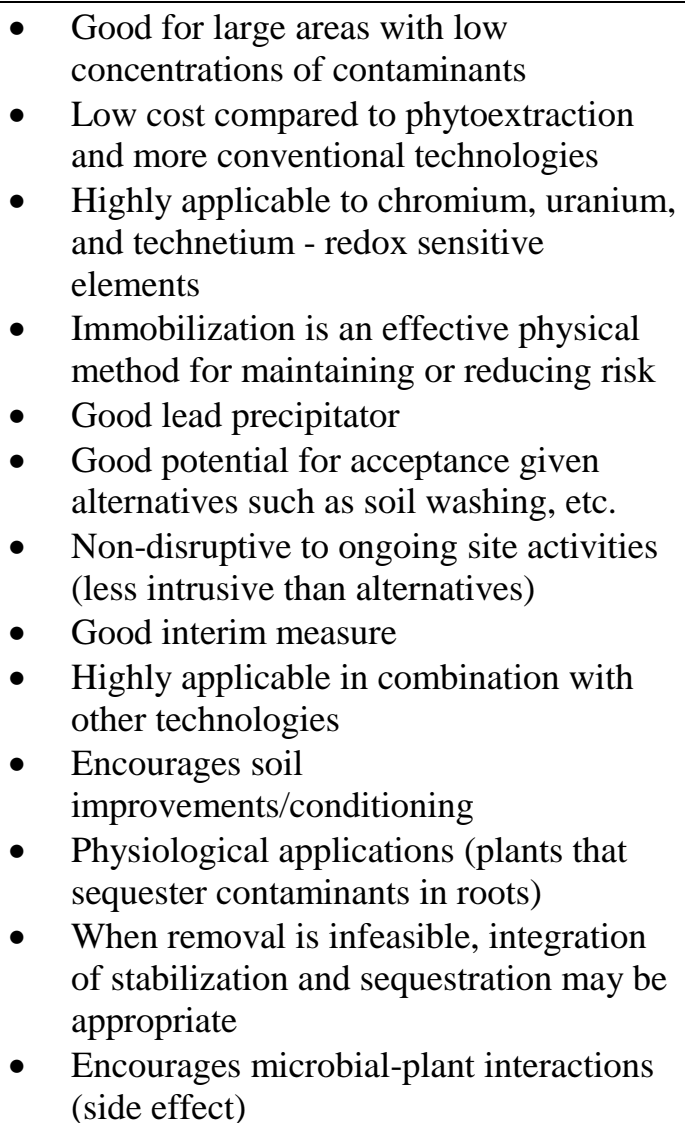 & 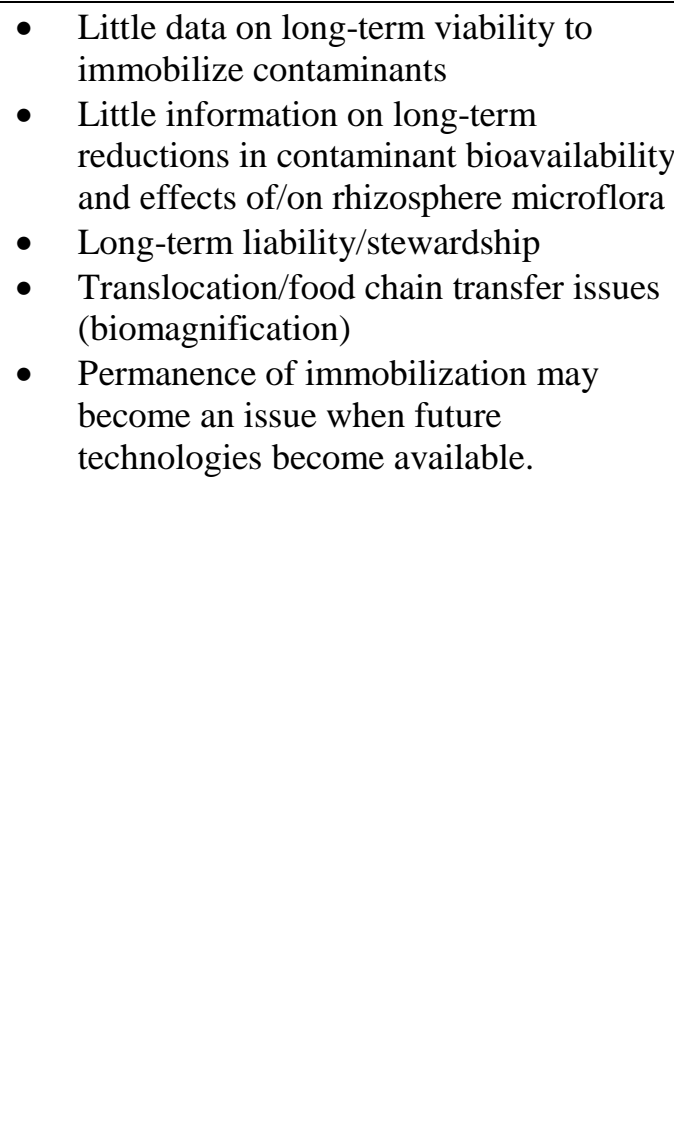 \\
\hline
\end{tabular}


The potential of phytostabilization is expected to be realized in large areas with low concentrations of contaminants that pose limited immediate risk to human health. It could have substantial appeal because its impact on the soil environment would be minimal or potentially beneficial compared to currently used technologies such as soil washing. The drawbacks are centered around our current lack of knowledge on the behavior of heavy metals and radionuclides in the rhizosphere, which leads to a poor understanding of long-term stewardship, bioavailability, and risk (Table $\mathrm{C}-1$ ).

\subsection{RESEARCH GAPS}

Both fundamental and applied research is needed in order to create regulatory/stakeholder acceptance for phytostabilization. Substantial information is available for nutrient metal behavior (copper, zinc, iron, etc.), but information on toxic metals and radionuclides fate and transport mechanisms within the root/plant or rhizosphere is limited. Participants discussed the need to study the uptake system as a whole in order not to lose information on synergistic effects. They discussed performance and time needed to achieve goals, risk management issues, regulatory acceptance, and commercial viability. While it may take five to ten years of research before issues of perceived risk can be addressed, the potential of phytostabilization as a stand-alone technology or as an integrated part of a remediation strategy is great enough to warrant a substantial investment. Also research components believed to be required in order to move forward were outlined. More specifically, the relevant fundamental and applied research needs include:

Plant/Soil/Contaminant Matrix - Data are needed to determine what types of plants are applicable to specific soils and specific contaminants. This should apply to both arid and humid climates. Better information on contaminant-specific hyperaccumulators is also needed.

Physiological Sequestration - Data are needed to determine contaminant storage in roots and the fate of metals in the various plant tissues (as opposed to adsorption at the root surface). Sequestration mechanisms in plants are not well known. Locations of sequestration in the root have been suggested to be in cell root walls (within the wall structure) or excluded in root vacuoles; lack of such fundamental knowledge as where sequestration occurs affects our ability to discern long-term metal bioavailability. We know that mycorrhizae are involved in acquiring nutrients and altering plant chemistry but little is known concerning their role in heavy metal/radionuclide uptake, transport, and sequestration.

Bioavailability - There is little research on the bioavailability of specific contaminants; there is also little data on the net mineralization over time. Such research would give scientists a better understanding of contaminant redistribution/recycling. Research is also needed to determine tree and plant load limitations (capacity/kinetics). Bioavailability may drive viability and stakeholder acceptance.

New Pathway Exposure - From a public/stakeholder perspective, there is currently more information on chlorinated solvents/organics food chain transfer than on inorganic food chain transfer. A better understanding of ecotoxicological effects and mechanisms of metal/radionuclide contaminant transfer through stabilization/sequestration is needed in order to move forward. More specific sampling techniques and analytical methods are needed to determine bioconcentration factors (to understand food chain transfer). 
Humification - We know that root turnover is rapid; at least one-third of the root mass is turned over every year. This material goes through a degradation process and is incorporated into the soil organic matter, but during this process of humification, little is known regarding the cycling of metals immobilized in the root mass. Similar concerns exist for contaminated above-ground material. This goes back to the issues of long-term effects on chemical speciation of metals/radionuclides sequestered in the plant tissue - mobile/labile versus recalcitrant pools.

Rhizosphere - The rhizosphere is a chemically and biologically complex environment. Yet the interactions between plant root, the microbial population, and soil are poorly understood. Little data exist to indicate the impacts that sequestration has on the microbial population in the root zone.

Fertilizers - Research on the effects of natural versus synthetic fertilizers on inorganic contaminant mobility (either for plant uptake or sequestration in soils). For example, if phytoremediation is to work, we need to amend sites with fertilizers; competitive ion effects (e.g., K versus Cs) can influence the degree of contaminant mobility in a given soil-plant system.

\subsection{RECOMMENDATIONS}

Basic scientific research is needed to understand what rhizosphere processes are important and if they can be utilized in a phytostabilization remedial action to yield an acceptable level of posttreatment risk to the environment. However, research funds and time are finite, and the data gaps identified above are extensive. Participants voted on which data gaps they thought were most critical in order to develop the basis and ability to determine an acceptable level of risk. Participants were given 15 points to allocate to any of the data gaps that were discussed during the earlier session. Each participant allocated 15 points to five data gaps in order of selected priority ( 5 points - highest, 4 points, 3 points, 2 points, and 1 point - lowest). The outcome of the vote is presented in Table $\mathrm{C}-2$.

From this exercise, the data gaps were regrouped and prioritized to develop recommendations for future work. Filling these data gaps will not necessarily enable phytostabilization to be broadly applied. Rather, addressing them will first yield an understanding of the viability of phytostabilization, under what conditions it is applicable and for what contaminants it could be used. These five areas are listed in order of highest to lowest priority and the first two are interchangeable. All panelists agreed that they address basic and applied scientific issues, and concerns important to regulators.

Long-Term Bioavailability - The objective of this need is to identify stable forms and biogeochemical factors that impact stability as well as the effects of the rhizosphere on weathering of immobilized contaminants. This need was identified as one of the most significant data gaps. Long-term effects of metal speciation and stability, complex and chelate formation in relation to bioavailability, and humification should be considered. The studies should determine the physical and chemical interaction of minerals and the recycling behavior of contaminants. The connection between solubility and bioavailability, the differences between bioavailable and recalcitrant pools, mobility from roots via leaching and recycling, and the mechanisms of bioavailability should be considered. There was some concern about whether tasks associated with these studies would be best conducted at a particular site (thus creating site-specific 
information) or in a lab (potentially applicable to multiple sites). A decision was not made on this topic.

Table C-2: Data Gaps Vote Outcome (in descending priority)

\begin{tabular}{|l|c|}
\hline DATA GAPS & VOTES \\
\hline Bioavailability & 52 \\
\hline Microbial/soil/plant interactions & 42 \\
\hline Physiological sequestration & 20 \\
\hline Rhizosphere understanding & 20 \\
\hline Toxicity related to food chain transfer & 14 \\
\hline Predictive model with realistic parameters & 13 \\
\hline New pathway exposure & 12 \\
\hline Crop maintenance - how do we get crops to grow? & 7 \\
\hline Humification & 6 \\
\hline Cycling and leaching - mobility from roots & 5 \\
\hline $\begin{array}{l}\text { Plant selection - what is out there and what works under what } \\
\text { conditions? }\end{array}$ & 4 \\
\hline $\begin{array}{l}\text { Long-term effects of chemical speciation (bioavailability vs. } \\
\text { recalcitrant pools) }\end{array}$ & 4 \\
\hline Plant/soil/contaminant matrix & 0 \\
\hline Research on the effects of natural vs. synthetic fertilizers & 0 \\
\hline
\end{tabular}

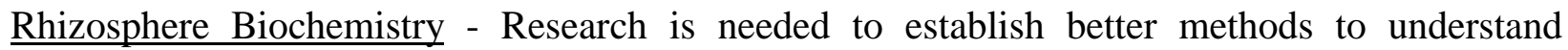
microbial, soil, and plant interactions in relation to contaminant mobilization/immobilization. It also focuses on techniques to understand contaminant transformation (enzymatic processes, chelates, etc.) from one compartment or pool to another. Technology development for ecological rhizosphere studies relative to metals and isotopes is needed. Plant and microbial relationships should be examined along with how plants and microbes influence each other's community. Clarification on metal uptake in plants is needed. A better understanding of metal partitioning in plants/microbes/soils and manipulation of the rhizosphere communities (inoculation) are also relevant.

Toxicity Related to Food Chain Transfer - An analysis is needed to compare the relative risk of contaminant bioaccumulation or biomagnification compared to no action or other technology alternatives. An ecological approach to better understand food chain transfer from trophic level to trophic level is required. Bioconcentration factors will be an important element of these investigations. Mechanisms for toxicity should be examined in a risk-based approach in order to determine impacts of metal speciation.

Physiological Sequestration in Plants - There is a need to characterize processes and examine environmental influences (such as climate, soil, and chemical) in a realistic context and apply resulting knowledge to microbial, soil, and plant interactions. Areas for study include cell wall, vacuole, exudates, transport, and root senescence and turnover. Contaminant redistribution in plants, and the impacts of plants/microbe exudates on bioavailability of rhizosphere/soil immobilized contaminants or plant induced chemical changes need to be addressed. 
Predictive Model - A model with realistic parameters is needed to move forward. The purpose of the model should be to estimate optimal conditions for phytostabilization and its viability for a given set of contaminant and environmental conditions. It should be a model that addresses both spatial issues (element distribution, and heterogeneities) and temporal issues (e.g., contaminant remobilization over time). It should also include "what if" scenarios, sensitivity analysis, and should address metal reactive transport and plant root influences.

These five broad research areas are not unique to the phytostabilization discussion panel. For instance, the phytoextraction group also suggested that research be conducted to better understand the complexities of the rhizosphere. However, the research outlined above is necessary in order to determine the viability of phytostabilization as a remedial action for metals and radionuclides and under what conditions could it be expected to achieve acceptable levels of risk.

\subsection{PARTICIPANTS}

Adriano, Domy, SREL

Angle, Scott, University of Maryland

Ainsworth, Calvin, PNNL (Team Leader)

Blaylock, Michael, EdenSpace

Brigmon, Robin, SRTC

Charoglu, Emily, EnviroIssues (Facilitator)

Cornish, Jay, MSE

Ebbs, Steven, Southern Illinois University

Fan, Teresa, U.C. Davis

Fellows, Bob, PNNL

Fuhrmann, Mark, BNL

Goswami, Dib, DOE - WA

Mays, David, Alabama A\&M State University

Miller, Michael, ANL-ER

\subsection{REFERENCES}

Batson, V.L., P.M. Bertsch, and B.E. Herbert. 1996. Transport Of Anthropogenic Uranium From Sediments To Surface Waters During Episodic Storm Events. J. Environ. Qual:1129-1137.

Dushenkov, S., D. Vasudev, Y. Kapulnik, D. Gleba, D., Fleisher, K.C. Ting, and B. Ensley. 1997. Removal of Uranium from Water Using Terrestrial Plants. Environ. Sci. Technol. 31:34683474.

Murphy, C. E., and R. C.Tuckfield. 1994. Transuranic Element Uptake And Cycling In A Forest Over An Old Burial Ground. The Science of the Total Environment. 157:115-124.

MSE-Technology Applications, Inc. 1999. Draft Work Plan - Revegetation of Mining Waste Using Organic Soil Amendments and Evaluate the Potential for Creating Attractive Nuisances for Wildlife. Prepared for the U.S. Environmental Protection Agency, National Risk 
Management Research Laboratory (Cincinnati, OH) and the U.S. Department of Energy, National Energy Technology Laboratory (Pittsburgh, PA). Document Control No. MWTP-157.

Neuman, D. R., F.F. Munshower, D. J. Dollhopf, S. R. Jennings, and J. D. Goering. 1996. Phytoremediation of Smelter Hill, Anaconda, Montana. Pages 285-296, In (ed. F.F. Munshower) Planning, Rehabilitation and Treatment of Disturbed Lands, Seventh Billings Symposium, March 17-23, 1996. MSU Reclamation Research Unit, Publication No. 9603.

Salt, D.E., M. Blaylock, N.P.B.A. Kumar, V. Duchenkov, B. D. Ensley, L. Chet, and L. Raskin. 1995. Phytoremediation: A Novel Strategy for the Removal of Toxic Metals from the Environment Using Plants. Biotechnology 13:468-474.

Smith, R.A.H., and A.D. Bradshaw. 1979. The Use of Metal-Tolerant Plant Populations for the Reclamation of Metalliferous Wastes. J. Appl. Ecology 16:595-612.

Wenzel, W.W., D.C. Adriano, D. Salt, and R. Smith. 1999. (Eds. D.C. Adriano et al.) In Bioremediation of Contaminated Soils. ASA No. 37, American Society of Agronomy, Madison, WI. 
APPENDIX D

MONITORING REPORT 


\section{APPENDIX D MONITORING REPORT}

\subsection{DISCUSSION FRAMEWORK}

The Phytoremediation Monitoring Team addressed three general monitoring topics, as requested by DOE:

- Methods and instrumentation for monitoring phytoremediation applications. Our first task was to review conventional methods, and then to explore more advanced and innovative methods for monitoring the success of phytoremediation applications. More simply put, our objective was to identify monitoring methods and instrumentation options for answering the questions: will it work at my site, how do I know it is working, and when is it done?

- Use of plants to monitor other remediation applications. The purpose of our second topic was to identify methods and instrumentation for using plants as a tool to monitor other remediation applications such permeable barriers and landfill covers.

- Use of plants to characterize contaminant distribution. Finally, the purpose of our third topic, similar to the second, was to identify methods and instrumentation for using plants as tools to characterize spatial and temporal patterns of contaminant distribution.

The Monitoring Team's discussions of these three topics followed a step-wise approach. During the initial breakout session, participants listed plant, soil, groundwater, and other parameters that may need to be monitored. They then identified issues pertaining to the selection of monitoring technologies, including what assumptions, constraints, and uncertainties should be considered. During the second breakout session participants classified and described standards and the more promising and advanced monitoring methods and instrumentation. The advanced technologies were grouped as either soil or groundwater phytoremediation, and then with respect to development status. "Development status" was categorized as follows:

- Already deployed. The technology has been demonstrated and deployed in the field.

- Already demonstrated, ready to deploy. The technology has been demonstrated in the field and is ready for field deployment with a phytoremediation application.

- Bench scale, ready for field demonstration. Lab development of the technology is complete and it is ready for a field demonstration. Deployment is one to four years away.

- Still conceptual; fundamental science needed. Several years of research are needed to test the concept. Deployment is five to ten years away.

The discussion of advanced technologies included other practical issues related to deployment such as commercial viability and regulatory acceptance.

Guidance for the team members for the third and final breakout session was as follows:

- Review, summarize, and then recast the findings of the earlier sessions as a list of key, bigpicture monitoring issues and technology gaps needing DOE's attention, and then, 
- Develop and rank a set of recommendations to DOE, or strategies, for the advancement of phytoremediation monitoring technologies.

\subsection{TOPIC 1: METHODS AND INSTRUMENTATION FOR MONITORING PHYTOREMEDIATION SITES}

Monitoring Team members expressed varied and sometimes contrasting perspectives on the feasibility and magnitude of monitoring phytoremediation sites. Team members also differed on the reasons, approaches, and technology needs for monitoring. An unconstrained listing of ideas during the initial breakout session ranged from general to very specific aspects of research monitoring, characterization or baseline monitoring, and implementation monitoring (monitoring the performance of a phytoremediation application). The discussion followed a more orderly development of ideas after the team chose to focus on implementation monitoring.

\subsection{Unconstrained Listing of Ideas}

The purpose of this exercise, which exhausted most of the first breakout session, was to encourage team members to loosen up, speak openly, and interact with one another. Participants were asked to answer three general questions: what should be measured, how do we measure it, and why are we monitoring? The exercise was intended as a facilitated free-for-all, and participants delivered. All suggestions were recorded for later discussion.

\section{What Needs to Be Monitored?}

Participants' lists of what should be monitored were later grouped as plant parameters, soil parameters, groundwater parameters, climate parameters, and other (Table D-1). These lists became the menu participants later scanned while selecting parameters considered important for implementation monitoring.

\section{How Do We Monitor?}

Team members identified several general issues and technology needs that should be considered in the process of selecting monitoring parameters and appropriate monitoring technologies.

\section{Technology Development Stage}

Selection of monitoring parameters and instrumentation depends on the stage or phase of the technology development process. Objectives and methodologies for research, characterization, implementation, and verification will differ. The selection of parameters, sampling designs, and measurement technologies will differ for laboratory versus field research, for point measurements versus areal measurements, for ground measurements versus remote sensing, and for treatability studies versus large-scale implementation, and eventually, verification of a phytoremediation project. Monitoring for a large-scale implementation may compare measures of long-term performance with model predictions. 
Table D-1: Unconstrained List of Phytoremediation Monitoring Parameters.

\begin{tabular}{|c|c|}
\hline Category & Parameters \\
\hline Plants & $\begin{array}{l}\text { - Concentration and partitioning of contaminants in plants - roots (sorbed or } \\
\text { bound and internal), shoots, stems, leaves } \\
\text { - Nutrient partitioning in plants when under stress resulting from contaminants } \\
\text { - Root depth, distribution, density, and diameter } \\
\text { - Plant abundance (density, cover, frequency, etc.), species richness, and diversity } \\
\text { - Classification of plants as indicators, excluders, and accumulators (determined } \\
\text { by looking at concentrations in soil and plants) } \\
\text { - Proportion of plant species sensitive to versus tolerant of contaminants; use to } \\
\text { manipulate the seed bank species planted as indicators, excluders, and } \\
\text { - Chlorophylatl levels in leaves; photosynthetic rates } \\
\text { - Comparison of changes in plant community structure relative to nearby non- } \\
\text { - Lentaminated areas }\end{array}$ \\
\hline Soil & $\begin{array}{l}\text { - Contaminant concentration in soil } \\
\text { - } \mathrm{pH} / \text { moisture/redox, which will generally affect bioavailability of contaminants } \\
\text { - Contaminated soil gasses }\left(\mathrm{CO}_{2} / \mathrm{O}_{2} / \mathrm{CH}_{4}\right) \text { and background control } \\
\text { - } \text { Cation exchility } \\
\text { phytoavailablility of contaminants. } \\
\text { - Soil bulk density, particle size, and other physical properties related to } \\
\text { phytoavailablility of contaminants. } \\
\text { - Competitive ions (e.g., potassium-cesium, calcium-strontium, nickel-cobalt, } \\
\text { zinc-cadmium, sulfate-selenate) }\end{array}$ \\
\hline $\begin{array}{l}\text { Ground- } \\
\text { water }\end{array}$ & $\begin{array}{l}\text { - Contaminant concentrations in groundwater } \\
\text { - Depth to groundwater and depth of plume } \\
\text { - Groundwater flow direction } \\
\text { - Water balance parameters }\end{array}$ \\
\hline Climate & $\begin{array}{l}\text { - Rainfall } \\
\text { - } \text { Barometric pressure } \\
\text { - Retosynthetically-active radiation } \\
\text { - Wind speed, etc. }\end{array}$ \\
\hline Other & $\begin{array}{l}\text { - Contaminant speciation/bioavailability } \\
\text { - Conditions of the soil/root interface } \\
\text { - Spectral changes - remote sensing } \\
\text { - } \text { Cass balance (soil vs. plant concentration) } \\
\end{array}$ \\
\hline
\end{tabular}




\section{Standard Sampling Methods}

Standard plant and soil sampling techniques may be inapplicable for phytoremediation. Standard methods are driven by regulations pertaining to measurement of total metal concentrations. These methods are expensive and sample numbers are often low. Phytoremediation monitoring will require large sample sizes (coverage), therefore, the feasibility of phytoremediation applications may rest on the development of new monitoring methods with emphasis on greater sample size, reduced uncertainty, and lower cost. Development of real-time and remote sensing methods may help increase coverage while reducing costs.

\section{Sampling Design}

The selection of monitoring parameters and instrumentation will depend on the purpose of the sampling design. Sampling designs for manipulative studies (replicated experiments), for modeling, and for passive monitoring certainly differ. Sampling designs for passive monitoring of a large-scale implementation will also vary depending on whether the purpose is time series analysis (e.g. intervention analysis), sampling for spatial patterns, or sampling for simple surveys (estimates of means and totals). Team members also suggested that the concept of representative sampling means something different to scientists, end users, and regulators.

\section{Ecological Risk Assessment}

The team identified needs with respect to selecting monitoring technologies for evaluations of ecological risks associated with phytoremediation:

- Research is needed on uptake processes, partitioning, and the influence of plants (species, growth stage, nutrient levels, etc.) on soil chemistry in the rhizosphere.

- Simple, reliable, robust models and adequate field data to verify models are needed.

- Overall, uncertainty in monitoring for risk assessments must be reduced.

\section{Other Issues and Needs}

The team offered a hodgepodge of other issues and needs, both general and specific, and some related less directly to the selection of monitoring technologies:

- Sampling a mixed system (such as groundwater) is different than sampling a non-mixed system (such as vadose zone soil).

- If plant communities are designed and grown for the purpose of monitoring stress, how long will the stress signature remain detectable? How long will plants acting as indicators, excluders, and accumulators survive in a competitive ecosystem? 10 years? 50 years?

- Implementation of monitoring protocols should be adaptable to an understanding of sitespecific conditions.

- The RTDF's work on phytoremediation of organics and the ITRC decision tree for phytoremediation of inorganics and radionuclides should be viewed as precedents for DOE's development of a monitoring framework for phytoremediation of inorganics. 


\section{Why Do We Monitor?}

This was the final question posed to the team during our initial listing of ideas. Their responses follow:

- Monitoring is required to demonstrate compliance with regulatory standards such as Maximum Contaminant Levels (MCL) and Maximum Contaminant Level Goals (MCLG) for soil and groundwater. Baseline or reference-area monitoring may also be needed to help establish cleanup standards and monitoring endpoints on a site-specific basis.

- Monitoring is required to demonstrate the effectiveness of phytoremediation, and, if plants are used as part of a monitoring technique for other remediation applications, monitoring plants located downgradient must demonstrate the integrity and effectiveness of barriers, and long-term containment.

- Using plants to monitor other remediation applications may reduce monitoring costs because plant samples that are either analyzed in the field or taken as interim samples may not require the same level of chain-of-custody as do closure samples.

- Monitoring is required to establish risk thresholds and then assure that the uptake and partitioning of contaminants in plants does not pose an ecological risk.

- Monitoring is also necessary to assure regulators that phytoremediation is not a "do-nothing" strategy. Regulatory acceptance of monitored natural attenuation is a precedent.

\subsection{Implementation Monitoring}

During the second breakout session, team members chose to focus the remaining discussion on implementation monitoring: monitoring the performance of a phytoremediation application. The following topics were discussed: monitoring goals, key parameters, standard methods, and advanced methods for soils and groundwater.

\section{Monitoring Goals, Key Parameters, and Standard Methods}

The team identified three goals or reasons for monitoring during implementation: performance monitoring, optimization monitoring, and risk monitoring. Key parameters were identified for each. Standard methods and problems were also reviewed.

\section{Performance Monitoring}

Performance monitoring is necessary to demonstrate whether phytoremediation has successfully cleaned up contaminated soil or groundwater to a predetermined standard, such as an MCL. Performance can be assessed by measuring changes in the mass balance of contaminant concentrations in the system, which requires diagnostic measurement capabilities, and/or by measuring the stress response in the system. Detection of changes in the contaminant mass balance requires measurement of concentrations and partitioning in plants (roots, stems, leaves), and concentrations in soil. For an application of groundwater phytoremediation, concentrations in groundwater and changes in the groundwater and soil water balance must also be monitored. A stress response in the system is detected by monitoring changes in plant health and/or changes 
in the structure and function of soil microbial populations.

\section{Optimization Monitoring}

The term optimization monitoring refers to the efficient management of a phytoremediation application. Optimization monitoring should lead to an iterative fine-tuning of the operation. Depending on the type of phytoremediation application, optimization monitoring may include the monitoring and management of soil fertility, irrigation, and other amendments. Optimization monitoring must be done in concert with monitoring the contaminant mass balance and plant stress responses.

\section{Risk Monitoring}

Risk monitoring is necessary to assure that accumulation of contaminants in plants does not create human health or ecological risks. Risk monitoring involves, at a minimum, identifying and monitoring potentially contaminated media, release and exposure pathways, and potential receptors.

\section{Standard Monitoring Methods and Problems}

The standard procedure for monitoring the contaminant mass balance consists of destructive sampling of plants, soils, and groundwater for laboratory analysis. This may be cost-prohibitive as the sole method for most phytoremediation applications because of the need for large sample numbers and frequent sampling. Therefore, as discussed previously, the feasibility of large-scale phytoremediation applications may rest on the development of new, innovative, more streamlined monitoring methods with emphasis on greater sample size, reduced uncertainty, and lower cost. However, the standard destructive sampling approach will continue to be used for calibration of indirect methods, for research on the contaminant-soil-root-plant system, and for research involving comparisons with innovative technologies.

\subsection{Implementation Monitoring - Advanced Methods for Soil Phytoremediation}

The team defined two categories of advanced monitoring methods and instrumentation for plants and soil: remote sensing methods and in-situ methods. The remote sensing category covers methods and instruments on airborne or satellite platforms, and ground-based versions of these instruments. The in-situ category, in contrast with standard destructive or ex-situ methods, refers to close-in techniques that essentially require touching the soil or leaf. Discussion included descriptions of the methods or instrumentation and then the development status (i.e. deployable, demonstrated, tested at bench-scale, or conceptual).

\section{$\underline{\text { Advanced Remote Sensing Methods for Plants and Soil }}$}

\section{Commercially-Available Spectral Reflectance and Thermal Infrared Instruments}

Remote sensing methods for detecting plant stress responses include spectral reflectance instruments, thermal infrared detectors, and laser-induced instruments. Spectral reflectance instruments are based on the plant reflectivity of sunlight. Hand-held, aerial, and satellite systems are commercially available. Spectral reflectance has been used for over 40 years in remote sensing of plant stress responses and is based on the simple reflectance of sunlight off plant canopies. Changes in specific wavelengths can be used directly or in simple algorithms to detect changes in the reflectance characteristics of plant canopies. For example, the use of the 
reflectance ratio $\mathrm{R} 750 / \mathrm{R} 700$ (reflectance at $750 \mathrm{~nm}$ divided by the reflectance at $700 \mathrm{~nm}$ ) has been used successfully to measure plant canopy chlorophyll levels in agricultural and forestry ecosystems. These systems are passive, commercially available, and ready to deploy. Thermal infrared (Thermal IR) detectors measure the temperature of healthy and stressed canopies. Aerial and satellite systems are commercially available.

A list of the capabilities of currently available, deployable systems (both aerial and handheld instruments) follows:

- These are passive systems that use reflectance spectra, multispectral and hyperspectral imaging.

- The sensors must be coupled with other techniques (e.g. ground truth measurements in the case of reflectivity).

- The systems are capable of monitoring relatively severe plant stress over large areas.

- These methods can be used to detect both spatial and temporal variability.

- Detection of species and plant community patterns is possible.

- These systems only detect foliage (above root zone).

- These systems are not currently a quantitative diagnostic tool for stress (i.e., do not identify contaminants or the source of the plant stressors).

Advanced Laser-induced Fluorescence Spectroscopy (LIFS) and Laser-induced Fluorescence Imaging (LIFI) Systems

Advanced remote sensing methods that are ready for field demonstration (deployment is one to three years away) promise even greater capabilities. These are active systems that, for example, stimulate plant or soil fluorescence with a light source such as laser. Improved diagnostic capabilities (detection of contaminant) is possible with systems that include (1) two or three instruments together, (2) currently available analytical techniques, (3) data fusion, and (4) neural net analysis. Quantitative measures for copper and zinc have been demonstrated in the greenhouse using active (fluorescence) and passive (reflectance) techniques. Field demonstrations and collection of data on existing phytoremediation sites will help prove the concept. Field demonstrations are needed, also, to distinguish contamination stresses from natural stresses such as drought or insect damage.

LIFS and LIFI instruments are based on the use of an ultraviolet (UV) laser to excite plant pigments producing fluorescence emissions in the blue, green, red, and far-red regions of the electromagnetic spectrum of visible and near-infrared (IR) light. Detection is with gated intensified CCD cameras, which allows measurement of the weak fluorescence return signal in daylight conditions. For LIFI, the data is in the form of images of the illuminated scene, due to fluorescence in specific bands. With LIFS, the fluorescence light is passed through a spectrograph, resulting in a high-resolution spectral analysis of the fluorescence light emitted by the sample. This allows subtle changes in the fluorescence signatures returned from different plants to be seen.

The hardware for the portable ground based systems is well developed. The LIFI system has actually been developed into a portable hand-held unit. It has been quite successful at detecting 
uranium contamination on surfaces and on the ground, but is now also being tested in plant stress studies. The LIFS system is portable, but has not been (though could be) developed into a handheld unit. Both systems have been used in field scenarios: in Poland, at Fort Irwin this month, and in many greenhouse tests at Epcot. Airborne laser-induced fluorescence systems have been built, but the hardware is not as advanced at this time. The weakest part of the fluorescence systems at this time is the data analysis methodology that follows collection of the raw data. Monitoring Team members did not believe that fluorescence techniques would replace classical reflectance techniques. Rather, the two techniques should be viewed as complementary methods.

\section{Laser-induced Breakdown Spectroscopy (LIBS)}

LIBS is another advanced remote sensing method that may be one to two years from deployment. This technology is based on a technique in which a high intensity UV laser beam is targeted on a specific leaf causing the leaf tissues to be vaporized. A spectrometer then is used to measure the emission lines of the specific elements present in the target site. This technology may be developed into a hand-held "real-time" measuring device for quantitatively determining the concentrations of contaminants in plant tissues.

$X$-ray Fluorescence (XRF)

XRF on aerial platforms and ground penetrating radar (GPR) are other new applications that are at least one to three years from deployment. XRF has already been demonstrated on a groundbased platform for certain minerals such as uranium, and could be used to detect other contaminants when coupled with other methods, but needs some work on resolution and precision. GPR could be used for metals detection in soil, but also needs better accuracy and precision. GPR will only detect large excursions in soil dielectrics and may be better for detecting drums and other objects.

\section{Genetically Engineered Fluorescent Markers}

Team members pondered genetic engineering concepts that will require fundamental science and are probably five to ten years away from deployment. Plants could be genetically engineered with fluorescent markers to enhance diagnostics, to quantify contaminants, and to distinguish natural from contaminant stresses. There has been very encouraging work in this area using genetically modified bacteria to detect ppb levels of mercury. Team members also believed that new analytical techniques should be developed and tested, specifically, neural net analyses of spectra and derivative analyses of spectra. These methods may offer greater diagnostics-useful in diagnosing particular soil contaminants-with remote sensing data.

\section{$\underline{\text { Advanced In-Situ Methods for Plants and Soil }}$}

\section{Chlorophyll Fluorescence (Kautsky Kinetics)}

Chlorophyll fluorescence instruments measure plant stresses but are not diagnostic for specific contaminants. Hand-held models that measure a small leaf area are commercially available in the U.S. and elsewhere. A three-year field demonstration in Poland determined that these instruments are quite useful for optimization monitoring (monitoring to fine-tune the management of a phytoremediation application). 


\section{Development of Field Applications of Standard Analytical Methods}

There remains a need to measure and predict the chemical speciation of metals in field soils, and to relate these measurements to bioavailability. Field soils are in all probability cycling through variable $\mathrm{pH}$ and Eh conditions. Traditional sequential soil extraction methods have not correlated with metal bioavailability to plants. This suggests that metal bioavailability to plants is governed by rhizosphere conditions, and metal availability to leaching and groundwater transport is governed by bulk soil conditions. There is a need to distinguish bulk soil from rhizosphere soil for speciation schemes. Deployment of such field applications remains two to three years away.

\section{Green Fluorescence Proteins (GFP)}

GFP genes can easily be attached to specific stress promoters in plants such that when the stress promoter is turned on, the GFP protein is produced and the reactive plant tissues will exhibit green fluorescence if illuminated with an UV or blue laser. The plant stress promoter described for the heat-shock phenomenon in plants has been demonstrated to be sensitive to heavy metal stimulation. Thus, it is possible that GFP genes might be attached to heat-shock promoters, which if turned on by heavy metals in soils, might function to produce a unique green fluorescent emission from plants. Because plants normally have a very low green fluorescent signature, the GFP expression would be a "smoking-gun" signature that heavy metals were present in the soil. Other GFP markers could be inserted into plants that might be sensitive to drought or plant pathogen stress promoters. This technology is still several years from deployment.

\section{Soil and Rhizosphere Microbiology: Fatty Acids and DNA Microarrays}

Soil microorganisms exist in intimate association with contaminants in soil and groundwater. Because both the function of individual microorganisms and the structure of the microbial community can respond to contamination and influence the fate of contaminants, an ability to characterize the structure and function of soil microorganisms in contaminated soil and groundwater is needed. With this ability, we could gain a better understanding of relationships among microorganisms in both bulk and rhizosphere soil, and plant-produced compounds, contaminant levels, soil conditions, and contaminant bioavailability. Improving our knowledge base of the soil-root-contaminant system would increase the probability of identifying and developing low cost, fieldable treatment techniques.

Currently, techniques such as phospholipid fatty acids (PLFA), whole soil fatty acid methyl ester (FAME), and denaturing or thermal gradient gel electrophoresis (DGGE, TGGE) are available for characterizing the soil microbial structure and its changes. These techniques, based on unique ratios of fatty acids found in cells and cell walls, can identify bacteria and fungi and provide qualitative and semi-quantitative estimates of the community structure. We can hypothesize that structure changes may be a useful indicator of contaminant bioavailability: the causal and structural feedback relationships among microbial community structural changes and soil contaminant levels, and how to best use this information at field sites, require further basic knowledge.

Estimates of changes in soil or groundwater microbial function caused by contaminant-induced stress may be obtainable by using DNA microarrays, a technique that uses specific DNA probes which are immobilized in a particular pattern on a glass or nylon surface or "chip". DNA microarrays are currently used in clinical and gene discovery research, but are at this time an 
emerging technology for environmental applications. In theory, DNA microarrays could rapidly identify DNA fragments extracted from soil and associated with a suite of stress-related genes in a soil or groundwater system. A "gene-chip" designed with 100 different genetic markers or bacterial species would be submersed into a sample and allowed to incubate for 1-2 hours. An automatic scanner would then read the gene-chip. Only specific gene markers or bacterial species would respond to specific heavy metals. If this technology were demonstrated, it might prove to be a very low-cost, rapid, and highly sensitive diagnostic test for specific heavy metals in soils or water. As with community structure approaches, a fundamental understanding of relationships among gene expression, contaminant concentration, contaminant speciation, and other interactions is currently lacking.

\subsection{Implementation Monitoring - Needs and Advanced Methods for Groundwater Phytoremediation}

\section{Monitoring Needs}

The Monitoring Team identified three key criteria for monitoring the performance of a groundwater phytoremediation application:

- Change in concentrations of contaminants in plants and in groundwater, either over time, or as a comparison with an unplanted but contaminated control plot.

- Change in plant health; a stress response.

- Change in water balance parameters including groundwater elevation, groundwater flow directions, and evapotranspiration. Change in groundwater level can be indicative of transpiration. A change in flow direction, such as from a water table depression, is indicative of transpiration (assuming knowledge of other factors that affect water levels, e.g., tides, barometric pressure, rainfall, etc.). Comparison of calculated PET (Potential Evapotranspiration) and AET (Actual Evapotranspiration) is indicative of vegetation maturity and the efficiency of water extraction.

Many of the advanced methods and technologies presented by the team to monitor soil mass balance (concentrations and partitioning in plants and soil) are also applicable for groundwater phytoremediation. Basically all of the plant diagnostics and plant stress monitoring methods described in the soil phytoremediation sections also apply to groundwater phytoremediation.

Implementation monitoring needs specific to groundwater applications primarily concern the water balance of a site. The team identified the following monitoring needs:

- Detection of small changes in groundwater level, flow direction, AET, and contaminant concentrations.

- Detection of contaminant phytoextraction at small, incremental depths through the aquifer. There is a widely held misperception that plant uptake of water only affects the upper surface of the water table. However, a small pressure change near the surface of the water table can deflect deep ground-water flow lines to the surface (i.e., analogous to groundwater discharge to lakes). There is a need to demonstrate that, because of such differential pressure gradients, phytoextraction removes contaminants from deeper in the aquifer. 
- Confirmation that phreatophyte roots are extracting water from the aquifer.

- As with pump and treat, phytoextraction from groundwater will lead to a shift in partitioning in aqueous and bound phases as groundwater is treated and equilibrium is re-established. An understanding of the rates that the equilibriums are re-established, in relation to phytoextraction rates, is needed to predict groundwater cleanup times.

- Monitoring of water flux through the vadose zone overlying contaminated groundwater, and through phytoremediation caps that consist of thick soil layers, are also needed.

\section{Commercially Available Methods}

\section{Nested Wells}

Standard or conventional methods for monitoring water level, flow direction, and contaminant concentrations, using piezometers, are not sensitive enough to match the scale of the process. The team recommended the use of nested wells with short screen sections that, together, can detect incremental changes in groundwater levels and in contaminant profiles.

\section{Evapotranspiration Monitoring}

The team identified several currently available ET (evapotranspiration) monitoring methods. Heat flow and heat dissipation instrumentation for measuring sap flow (an indicator of transpiration) on single stems are currently available. However, scaling is a problem. Field demonstrations of methods for extrapolating plant stand and community transpiration from sap flow measurements on single stems are needed. Whole plant gas exchange methods for monitoring ET have also been demonstrated. Again, methods for extrapolation to the plant community scale are needed. Other currently available methods mentioned by the team include lysimetry, porometry, eddy correlation, and Bowen ratio.

\section{Other Available Water Balance Techniques}

The team discussed three additional, currently available water balance monitoring techniques: stable isotopes, other tracers, and new applications of standard techniques. Stable isotope ratios (e.g. deuterium, oxygen) of water in plants can be used to determine if the source is from rainfall or groundwater. Other tracers such as bromide are currently used to measure flow patterns in field experiments and could be extended to phytoremediation field studies. New methods consist of standard groundwater analytical techniques adapted for field applications.

\section{Methods Ready for Field Demonstration}

The team identified two instruments for monitoring water movement in soil and groundwater that may be two to three years from deployment: heat flow instruments and saturated flow probes. Field demonstrations of heat flow or heat dissipation instruments for monitoring flux in the unsaturated zone are underway. Groundwater (saturated zone) flow probes that can measure groundwater flow at point sources (i.e., within a small well) have been developed for measuring flow in complex geologies and could be field-tested to interpret ET effects on groundwater flows.

\section{Methods Requiring Fundamental Science}

As described in the section on soil monitoring methods, there are convincing arguments that 
understanding the structure and function of the microbiology of a contaminated system could lead to a monitoring strategy based on stresses imposed by contaminants. There are emerging technologies for characterizing the structure and function of microorganisms in environmental systems, but these require further research to understand the relationships among environmental microbiology and governing processes that are important in environmental applications. As with soil, PLFA, FAME, DGGE, and TGGE are available technologies that can be used to monitor microbial changes. DNA microarray technologies that have been developed for clinical applications may have the potential to be modified for environmental applications. All of these require further research to determine their utility in monitoring.

\subsection{TOPIC 2: THE USE OF PLANTS TO MONITOR OTHER REMEDIATION APPLICATIONS}

\subsection{Introduction}

In addition to the evaluation of methods for monitoring phytoremediation sites (Topic 1), DOE asked the Monitoring Team to identify methods and instrumentation for using plants as a tool to monitor other remediation applications such as permeable barriers and landfill covers. Overall, team members believed that methods and instrumentation presented under Topic 1 (Section 2) for plants diagnostics and for monitoring plant stress responses would also be applicable for the monitoring of other remediation technologies. The team proposed three applications of these techniques for monitoring other remediation applications: up- and down-gradient comparisons, the use of plants to monitor engineered disposal cells, and seed bank manipulation.

\subsection{Comparison of Plants Up- and Down-Gradient}

The team suggested that the most obvious application using plants as monitoring tools would be a comparison of contaminant concentrations in plants up- and down-gradient of a groundwater plume undergoing remediation. Monitoring the integrity of permeable reactive barriers and impermeable barriers was of particular interest. Some variations on this theme were mentioned. One was to plant genetically altered plants (see section on GFPs under Topic 1) around the perimeter of remediated sites. Another was to use dendrochemistry of tree cores to monitor the progress of groundwater remediation. If the dendrochronology is good (if growth rings can be dated) then retrospective monitoring and time series methods (e.g., intervention analysis) are possible. The final suggestion was to compare spectral signatures in plants up- and downgradient to determine levels of stress. This could be used as a mapping or detection tool for managing contaminants in surface soils. 


\subsection{The Use of Plants to Monitor Engineered Disposal Cells}

The team proposed using plants to monitor the performance of engineered disposal cells. Deeprooted plants grown along the perimeter of a disposal cell could detect leakage into shallow aquifers. Plants grown at the base of the disposal cell side slope could also be used to monitor and manage runoff. Sampling of plants growing on the disposal cell cover may detect biointrusion of waste. Remote sensing technologies may be useful for coverage of large areas, using either hand-held instruments in the field or aerial/satellite platforms.

\subsection{Seed Bank Manipulation}

Seed bank manipulation refers to the placement of indicator plant species with varying tolerance to contaminants in the understory seed bank. At the time of harvest, a survey of the species composition may indicate the progress of remediation. Spatial heterogeneity of contaminants and of other factors affecting the growth and survival of indicator species can also be observed. Team members suggested that the primary use of seedbank manipulation might be monitoring of phytoremediation sites.

\subsection{TOPIC 3: THE USE OF PLANTS FOR CHARACTERIZATION}

\subsection{Introduction}

The team explored methods and instrumentation for using plants to characterize spatial and temporal patterns of contaminant distribution. Team members suggested that methods and instrumentation outlined above for diagnostics of contaminants in plants and plant stress response monitoring may be applicable. Potential applications are described in this section.

\subsection{Use of Plants to Characterize the Extent of Soil Contamination}

Plant diagnostics and stress response methods could be used to detect the extent of contamination. However, several team members considered this primarily as a screening method leading to more efficient sampling designs using more accepted conventional analytical techniques.

\subsection{Use of Plants to Monitor Airborne Distribution}

The team proposed the sampling of bark tissue to characterize and monitor airborne distribution of contaminants. Bark tissue sampling would indicate contaminants in phloem (not uptake in xylem) and possibly wind-blown particulates lodged in cracks. Wind-blown particulates can be incorporated in rough-textured bark of conifers such as pinyon and juniper in the Southwest. For trees that slough bark regularly, only current-year detection is possible. Mosses and lichens on soil and plants that bioaccumulate metals and radionuclides may also be indicative of airborne contaminants. These applications would primarily be limited to detection of the presence or absence of contaminants.

\subsection{Dendrochemistry}


Analysis of annual growth rings of trees and woody shrubs might be used to reconstruct the history of contamination dispersion (retrospective monitoring) as well as to characterize current contaminant distribution. Retrospective monitoring via dendrochemistry has been used successfully for metals in groundwater at Aberdeen Proving Ground, and using C-14 as an indicator of short-lived airborne radionuclides at Hanford.

\subsection{ISSUES AND RECOMMENDATIONS}

During the third and final breakout session, the Monitoring Team was asked to review, summarize, and then recast the findings of earlier sessions as a list of key, big-picture monitoring issues and technology gaps needing DOE's attention. The Team then developed and ranked a set of recommendations, or strategies, for the advancement of phytoremediation monitoring technologies.

\subsection{Key Issues, Needs, and Technology Gaps}

\section{$\underline{\text { Models }}$}

More robust models are needed for performance predictions. Models should differentiate between rhizosphere processes and bulk soil processes because the microbiology and chemistry in the rhizosphere differs from the bulk soil. Such models would necessarily require some estimation of root growth, density, and distribution.

Current widely used groundwater flow and solute-transport models (e.g. MODFLOW) are an important first step in trying to model the affect that plants have on groundwater flow systems. In many cases, however, the only process accounted for by the model is transpiration, and this is usually modeled using a simple uptake function that may not necessarily reflect actual plant water uptake processes. Additional confirmation of existing models is needed, perhaps followed by the development of more sensitive models.

Alternatively, phytoremediation could be treated as a form of 'contaminated land husbandry.' Treatability studies could be designed to predict parameters such as yield, rate of removal, projected time to reach remediation goal, site suitability, and projected end use of the sites. End users could then use the results of the treatability studies to help them choose which technology to deploy at their sites.

\section{Sampling Designs.}

Field sampling designs are well established for conventional destructive sampling and analytical techniques. Similarly, sampling designs and measures of uncertainty must also be considered in the development and deployment of more advanced monitoring technologies. Thus far, an inherent tradeoff in low input (and therefore low cost) biological treatments compared to more intensive treatment options is that longer treatment times may be needed. Consequently, monitoring, and therefore sampling, are usually seeking to quantify relatively small differences in a given period of time. For these reasons, sampling and monitoring techniques that are appropriate and well established for conventional treatments may not be appropriate for 
phytoremediation technologies. Sampling designs that provide guidance on the temporal and spatial density as well as providing measures of uncertainty must be considered in the development and deployment of more advanced monitoring technologies.

\section{Decision Framework for Phytoremediation Designs.}

DOE should develop a tool for evaluating the applicability and practicality of advanced and innovative monitoring techniques, a tool that focuses on end-user needs. The tool could be in the form of a decision framework consisting of a series of steps and decision points leading from site characterization, through risk assessment, to site-specific phytoremediation design, and then to applicable performance and optimization monitoring techniques. DOE should focus research resources on technology gaps and needs that emerge from iterative exercises involving regulators, end-users, and researchers stepping through this process at specific DOE sites. Part of this group should participate in the processes at all (or at least many) sites to facilitate transfer of other ongoing approaches and lessons learned at other sites.

\section{$\underline{\text { Regulatory Acceptance of Innovative Monitoring Methods. }}$}

Regulatory agencies should be participants in the selection, development, and deployment of new monitoring technologies.

\section{Need for Well-Orchestrated Field Tests.}

Controlled laboratory experiments are necessary for identifying and understanding important processes. DOE should recognize that in biological systems, field results may differ from laboratory-based predictions. To contend with this, integrated test sites that share the costs associated with rigorous independent monitoring and treatment approaches are needed (e.g., SERDP). These field tests should include direct side-by-side comparisons of currently accepted technologies and the newer technologies being developed. Only then can the essential data be acquired on a new technology that would speed the acceptance for regulatory purposes. Integrated field tests should include multiple monitoring technologies on the same treatment technologies, for both valid monitoring assessments and also for improved understanding of the underlying processes. For this to be worthwhile, DOE should sustain funding through the entire technology development process, including basic research, applied research, and technology transfer. Finally, throughout the testing program, DOE must have end-user and regulator buy-in to be able to apply alternate sampling and monitoring methods if field test are successful.

\section{Monitoring During Implementation for Process Optimization.}

As DOE develops a phytoremediation program, there is a clear need to differentiate between monitoring for characterization, implementation, optimization, and verification. Monitoring during implementation of a phytoremediation application should help to optimize process efficiency and save money. Modeling can help to minimize the number of wells or soil samples. 
Monitoring should be a part of contingency planning, to determine what will be done if trees/plants die. Monitoring strategies are also needed to address speciation and associated effects on risk.

Frequency and Duration of Monitoring.

A key issue is to determine how often and for how long monitoring is necessary to evaluate whether a phytoremediation system is "working". Because of spatial and temporal variability, it is difficult to show statistically significant changes in soil or groundwater concentrations between sequential sampling times.

\section{$\underline{\text { Real-Time Data Collection. }}$}

There is no consensus of the need for or value of real-time data collection for implementation monitoring. Real-time methods can be developed so they are placed intricately within the phytoremediation system. If used, real-time data collection should be well integrated with decision implementation process. Research is still needed to develop real-time methods of data collection for parameters such as sap flow and leaf temperature.

\subsection{Recommendations}

Team members integrated and consolidated issues to develop a list of recommendations to DOE. Team members then ranked recommendations in order of importance. Each team member was allowed five votes. Team members dispersed their votes as they wished. For example, a member could use all votes for a single recommendation, or allocate one vote to five recommendations. Voting percentages are shown in parentheses.

\section{Sponsor Field Tests (41 percent)}

DOE should sponsor well-orchestrated field tests of monitoring technologies and certify those that meet the required standards. Specifically, DOE should:

- Conduct side-by-side testing of standard and innovative monitoring technologies.

- Coordinate monitoring and treatment evaluations so that all site users will have access to common data.

- Test multiple techniques for monitoring at a single site; compare cost and performance.

- Provide opportunities for end user and regulator participation in the field tests to obtain their buy-in. Explore opportunities for having regulatory agencies agree to apply an alternate cleanup standard if a field test works (like the U.S. EPA-ACAP program).

- Build on phytoremediation and monitoring work performed in Poland by field-testing the Polish technologies (such as chlorophyll fluorescence) in the U.S.

- Look for opportunities to build integrated tool kits of monitoring instruments. 
- Consider strategies for DOE to sustain funding throughout the entire technology development process.

- Consider the availability of integrated (e.g., SERDP) test sites that can be used to test both phytoremediation and monitoring technologies.

\section{Fund More Work on Using Plants as Characterization Tools (17 percent)}

Monitoring costs may be reduced by using plants with varying tolerances to contaminants to provide evidence of the success or failure of a program. Seedbank manipulation, for example, involves the use of plants with varying levels of tolerance (may only be useful for inorganic contaminants) sowed into the soil at the set-up stage of a phytoextraction effort. They will then reside in the soil and germinate each harvest when the canopy is opened up. The presence of the most sensitive vegetation will be an indicator of a reduction in bioavailable metals. Spatial distribution may also be easily monitored. This may be implemented on sites, which are not an immediate health risk, where contaminant status is low, because it does not provide an instant indication.

Indicator plant: internal metal concentration $=$ soil metal concentration

Accumulator plant: internal metal concentration > soil metal concentration

Excluder plant: internal metal concentration $<$ soil metal concentration

\section{Define Elements of an Effective Monitoring Protocol (15 percent)}

DOE should acknowledge that a monitoring protocol must:

- Address both the instrumentation to be used and the sampling design or protocol (e.g., frequency, how long, how many samples, what scale).

- Consider both contaminant speciation and bioaccumulation.

\section{Develop a Common Language (11 percent)}

Use the terminology "monitored phytoremediation" to indicate that phytoremediation is not a "do-nothing" option.

\section{Improve Coordination and Communication ( 7 percent)}

- Improve coordination among DOE sites with existing or proposed phytoremediation projects.

- Conduct a workshop for technology developers and end users to devise common measurement parameters and protocols.

- Include all contaminants present at the sites (to fully account for differences in plant uptake).

- Develop a central information repository that includes a database of plant capabilities and sources of information on phytoremediation. 
- Facilitate information exchange through a web site and chat room. Build on and/or include links to existing web sites: ITRC, RTDF, U.S. EPA SITE program, etc.

- Consider using the Air Force Center for Environmental Excellence (AFCEE) program on natural attenuation as a model for structuring the effort and information exchange.

\section{Determine Why Monitoring Is Being Conducted ( 7 percent)}

- Recognize that monitoring is conducted for a variety of purposes (e.g., research, site characterization, implementation of a remediation system, and verification), and that the methods and tools used for each purpose are different.

- The objective of research monitoring: reduce parameters that need to be sampled in the field, and streamline/standardize techniques for implementation monitoring.

- Key research issues: monitoring and measurement of root distribution; studying hyperaccumulation mechanisms - how plants uptake contaminants; studying how speciation affects risk in an ecosystem; and relating bioavailability to risk.

- Objectives of implementation monitoring (monitoring during remediation): track performance, optimize process efficiency, and save money.

Develop a Decision Framework for Phytoremediation Designs (2 percent)

Develop a decision framework to help end users select appropriate monitoring technologies and sampling protocols. Ensure that monitoring is fully integrated into the design process for a site. Use the decision framework to identify site-specific technology gaps and needs.

\subsection{PARTICIPANTS}

John Blake, DOE - Savannah River

Gene Capelle, DOE - Nevada

Kris Geller, NJ DEP

Jennifer Kauffman, EnviroIssues (Facilitator )

Jim Landmeyer, USGS - Columbia, SC

Tracy Punshon, SREL

Mike Reynolds, Cold Regions Research and Engineering Lab, USACE

Peter Richter, Technical University - Budapest, Hungary

Aleksandra Sas-Nowosielsla, Institute for Ecology of Industrial Areas, Poland

Andrew Schuerger, Dynamac Corp.

Laura Skubal, ANL - Chicago (Recorder)

Jody Waugh, Roy F. Weston, Inc., Grand Junction Office (Team Leader)

Neal Yancey, INEEL 


\section{APPENDIX E}

DEPLOYMENT OF PHYTOREMEDIATION AT THE 317/319 AREAS ARGONNE NATIONAL LABORATORY-EAST (ANL-E) 


\section{APPENDIX E \\ DEPLOYMENT OF PHYTOREMEDIATION AT THE 317/319 AREAS ARGONNE NATIONAL LABORATORY-EAST (ANL-E)}

\subsection{INTRODUCTION AND BACKGROUND}

The 317 and 319 Areas are located on the extreme southern end of the ANL-E site, immediately adjacent to the DuPage County Waterfall Glen Forest Preserve. The 317 Area is an active hazardous and radioactive waste processing and storage area. In the late 1950s, liquid waste was placed in the unit known as the French Drain. Since that time, this waste has migrated into underlying soil and groundwater. The principal environmental concern in the 317 Area is the presence of several VOCs in the soil and groundwater and low levels of tritium in the groundwater beneath and downgradient of the site. The 319 Area Landfill and French Drain are located immediately adjacent to the 317 Area. The principal environmental concern in the 319 Area is the presence of radioactive materials in the waste mound, in the leachate in the mound, and in the shallow groundwater immediately downgradient of the landfill. Several interim actions have already been implemented in this area to reduce the VOC and tritium releases from these areas, as the result of the Resource Conservation and Recovery Act (RCRA) Facility Investigation (RFI) conducted from December 1994 through September 1996.

The final action to complete corrective action for removing contamination in the 317 and 319 Areas is the deployment of phytoremediation. For this application, phytoremediation is defined as the engineered use of natural processes by which woody and herbaceous plants extract pore water and entrained chemical substances from subsurface soils; and degrade, sequester, and transpire them along with water vapor into the atmosphere. In 1999, EM-40 and EM-50, through the Accelerated Site Technology Deployment (ASTD) Program, jointly funded the deployment of a phytoremediation system in the 317/319 Areas with the following objectives: (1) minimize water infiltration into the 317 Area French Drain soils, some of which was treated previously by soil mixing and iron addition; (2) stabilize the treated soil surface in the 317 Area French Drain area to prevent erosion, runoff, and downstream sedimentation; (3) hydraulically contain groundwater migration and continue remediation of the residual VOCs within the 317 Area French Drain and downgradient of the French Drain; and (4) hydraulically contain the tritium and VOC plumes south of the 319 Area Landfill.

The installed system consists of plantings of shallow-rooted hybrid willows and special deeprooted hybrid poplars. This system will prevent the further generation of contaminated groundwater in the source area by degrading the contaminants, and will also prevent the further migration of these plumes by removing groundwater from shallow saturated zones downgradient from the source area.

Soon after DOE funded the project, the U.S. EPA and DOE agreed to include this remediation technology deployment in the projects evaluated by the U.S. EPA Superfund Innovative Technology Evaluation (SITE) Program. Under this program, the U.S. EPA will independently monitor and evaluate the technology's performance at the ANL-E 317/319 site in addition to the scheduled monitoring activities conducted by ANL-E. 


\subsection{TECHNOLOGICAL APPROACH AND EXPECTED RESULTS}

The use of trees to remediate and contain contaminated groundwater has been successfully demonstrated in treating contaminated groundwater. Applied Natural Sciences, Inc. (ANS) demonstrated the use of phreatophytic trees (i.e., plants such as poplars and willows that do not rely on precipitation water but seek water deep in soils) with its TreeMediation ${ }^{\mathrm{TM}}$ and TreeWell ${ }^{\mathrm{TM}}$ systems, that use a unique and patented process to enhance the aggressive rooting ability of selected trees to clean up soil and groundwater up to $50 \mathrm{ft}$ deep. Under a CRADA, ANL-E and ANS have researched phytoremediation applications since 1994.

The hydrogeology at the $317 / 319$ site is a complex framework of glacial tills interlaced with sands, gravels, and silts of varying character, thickness, and lateral extent. The subsurface is a complex arrangement of approximately $60 \mathrm{ft}$ of glacial geologic deposits over Silurian dolomite bedrock. The glacial sequence is comprised of Lemont drift overlain by the Wadsworth Formation. Both units are dominated by fine-grained, low-permeability till. Permeable zones of varying character and thickness are present in each. These materials range from silty sands to sandy, clayey gravels to gravelly sands. In some locations, pure silt was encountered. If deep enough, this silt was saturated, and it is assumed to play in important role in the flow of groundwater in the study area. The permeable zones have a wide range of shapes, their thicknesses range from less than $1 \mathrm{ft}$ to roughly $15 \mathrm{ft}$, and they have limited lateral extent.

On the basis of a preliminary agronomic assessment, hybrid willow and hybrid poplar trees were selected for the system. In the summer of 1999, a total of approximately 800 trees were planted in three locations: the 317 Area French Drain, south of the 317 Area French Drain and 319 Area Landfill (the 317 and 319 Hydraulic Control Areas), and in the waste trench south of the 319 Area Landfill. Figure 1 shows the location of the plantings.

In the 317 and 319 Hydraulic Control Areas, poplar trees were planted in boreholes spaced $16 \mathrm{ft}$ apart drilled down to the contaminated aquifer using ANS's TreeWell ${ }^{\mathrm{TM}}$ system. This technology was selected, in consideration of the hydrogeological setting of the site, to target root growth in the contaminated glacial-drift permeable unit approximately $30 \mathrm{ft}$ deep. The poplars were planted in 2-ft diameter caisson boreholes lined with plastic sleeves in order to direct the roots exclusively to the main contaminated aquifer. These boreholes were filled with a mixture of topsoil, sand, peat, and manure to promote root growth and tree development. The capillarity of the mixture provides an added benefit of drawing water to where it is available to the young trees. Figure 2 presents a diagram of a TreeWell ${ }^{\mathrm{TM}}$ installation, and Figure 3 shows the borehole being drilled in the 317 Hydraulic Control Area.

Willow trees were planted in the two other areas in boreholes spaced $10 \mathrm{ft}$ apart at the surface in areas of relatively shallow groundwater contamination, without the plastic liner in order to address the contamination and moisture in the whole soil profile. All boreholes were also provided with aeration tubes to ensure a supply of air to the growing roots.

To support the deployment of the phytoremediation system, a groundwater flow model was developed. Flow modeling was conducted initially to model the natural, transient changes in the flow field caused by seasonal changes in recharge to the aquifer. The model was calibrated to 
approximately 10 years of water level measurements from site monitoring wells. Anticipated effects of the phytoremediation system were included. The model, updated to include the as-built configuration of the phytoremediation system, indicates that the as-built plantation will provide hydraulic containment even during the winter months when the trees are dormant.

Planting phreatophytic trees at the capillary fringe in the year 1999 is expected to provide full hydraulic control by the year 2002-2003 and be self sustaining for the full expected life of the engineered plantation. Hybrid poplar and hybrid willow trees typically have a life span of about 40 years.

ANL-E proposed to establish a groundwater management zone (GMZ) that incorporates the 317/319 Areas. Once the Illinois EPA (IEPA) approves the GMZ, periodic sampling of the wells that bound the zone is expected to show that the groundwater outside the zone meets the Tiered Approach to Corrective Action Objectives (TACO) Tier 1 cleanup objectives set by the Illinois Administrative Code. ANL-E will continue its corrective actions inside the GMZ until such time that the IEPA determines that the actions can be discontinued.

ANL-E installed 48 groundwater monitoring wells on the phytoremediation project site to track the performance of the phytoremediation system. Monitoring activities have started at the completion of the construction phase and include recording climatic conditions, plant growth and transpiration rates, soil moisture, VOC degradation in plant tissue, groundwater elevation and concentration of VOCs and tritium, ambient air concentration of VOCs and tritium, and transpirate concentration of VOCs. Root development will be observed through specially designed viewing ports (minirhizotrons). This monitoring program is a combined and independent effort between ANL-E (funded by the ASTD program and EM-40) and the U.S. EPA SITE program.

At the end of the remedial process, when a final analysis will verify the absence of the contaminants in the biomass, the trees will be cut down at ground level, chipped, and air dried. The roots will be left in place to decay through natural processes and the chips will be reused on site as mulch for the planting of native prairie species, in accordance with the planned final restoration of the area.

\subsection{TECHNOLOGY ADVANTAGES}

The conventional, baseline method of remediation at the target 317 and 319 Areas included placing a cap and installing extraction wells (pump-and-treat) downgradient of the contaminant plumes from which contaminated water would have been withdrawn and discharged to a lift station, which pumps water to Argonne's waste treatment plant. The subsurface at the site is comprised of units of widely varying lateral or vertical extent, with gradational or sharp transitions in permeability. With phytoremediation, the fibrous nature of roots allows the trees to penetrate and remediate both the relatively fast-flowing pore spaces and the less permeable zones. Fundamentally, this distinguishes phytoremediation from extraction wells, which remove water mainly from the most permeable aquifer media. 
The plant based system is expected to have lower operating and maintenance costs: preliminary evaluations put the cost savings over the lifetime of the deployment at 50 percent compared to the baseline approach. A significant cost saving is the avoidance of secondary waste (pumped groundwater) and related treatment.

Additional advantages of the phytoremediation system are (1) the ability of trees to also actively promote and assist in the degradation of the contaminants at the source area, which the baseline asphalt cap would not do, and (2) the optimal fit of the vegetation with the planned future land use of the contaminated site and adjacent areas, as the phytoremediation plantation will contribute to increase soil fertility to host subsequent prairie species.

\title{
4.0 CONTACTS
}

\author{
M. Cristina Negri \\ Environmental Engineer/Soil Scientist \\ Energy Systems Division \\ Argonne National Laboratory \\ 9700 S. Cass Ave., Argonne, IL 60439 \\ Tel: (630) 252-9662 \\ Fax: (630) 252-9281 \\ negri@anl.gov \\ James B. Wozniak \\ Project Manager \\ Environmental Health and Safety Division \\ Argonne National Laboratory \\ 9700 S. Cass Ave., Argonne, IL 60439 \\ Tel: (630) 252-6306 \\ Fax: (630) 252-9642 \\ jwozniak@anl.gov \\ Web address: \\ www.ipd.anl.gov/biotech/phyto.html
}




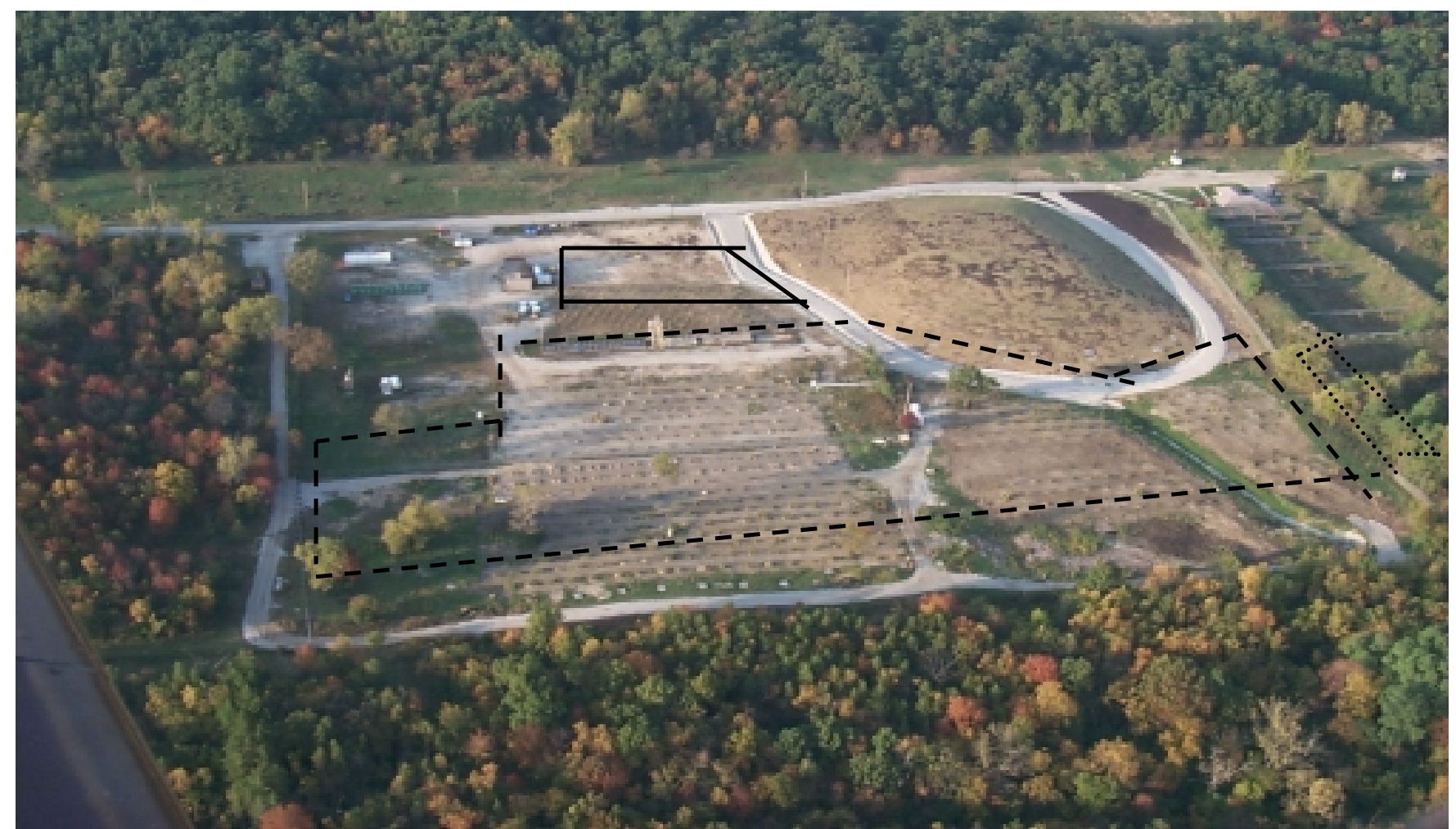

317 French drain area

- - - 317/319 Hydraulic control area 319 Waste trench area

Figure 1: Aerial Picture of the 317/319 Areas Phytoremediation Project and Location of Plantings. 


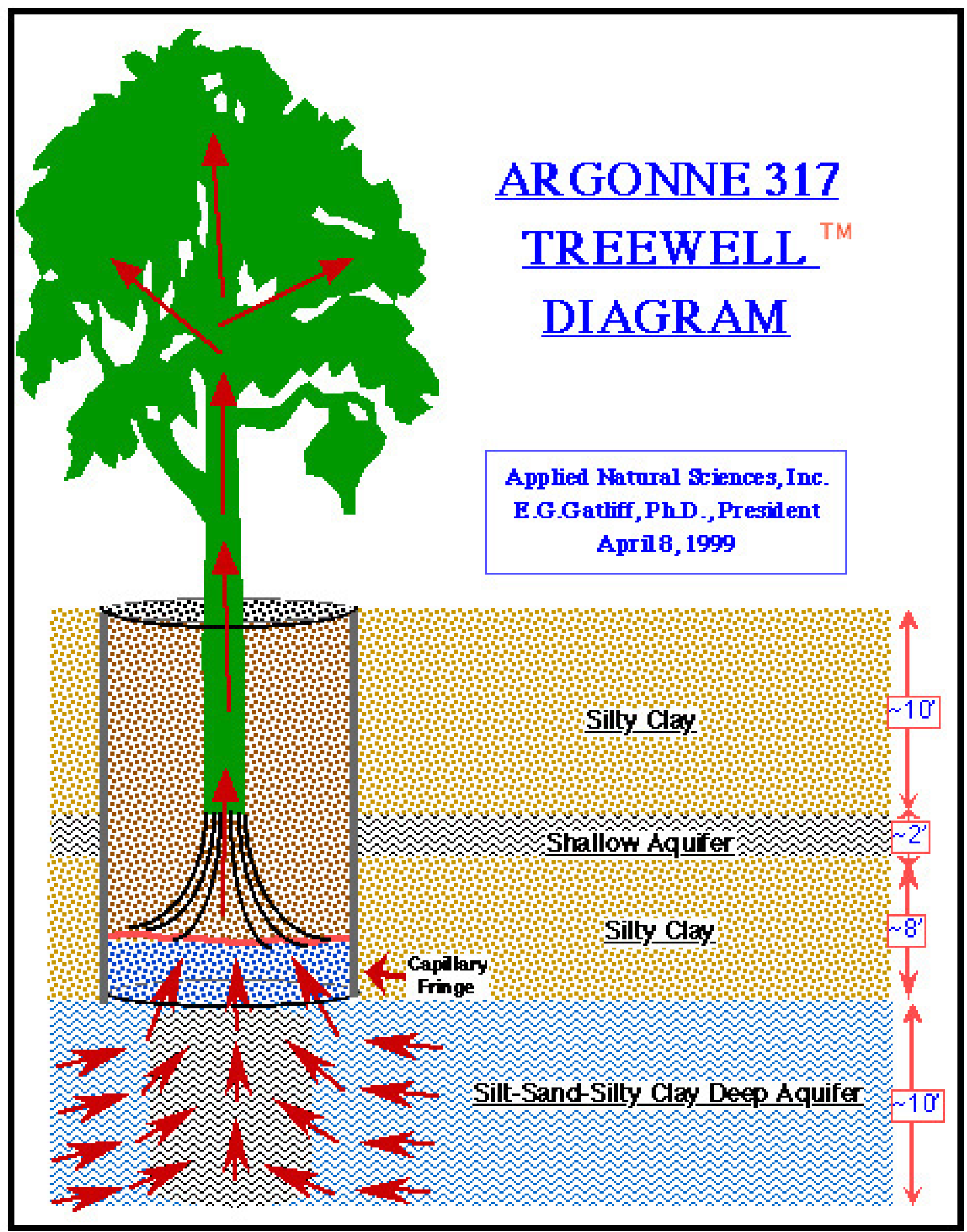

Figure 2: Schematic of a $\underline{\text { TreeWell }}^{\mathrm{TM}}$ installation.

The TreeWell ${ }^{\mathrm{TM}}$ methodology is patented. For more information, please call Dr. Edward Gatliff at (513) 895-6061. Diagram provided by Dr. Edward Gatliff, Applied Natural Sciences, Inc. 


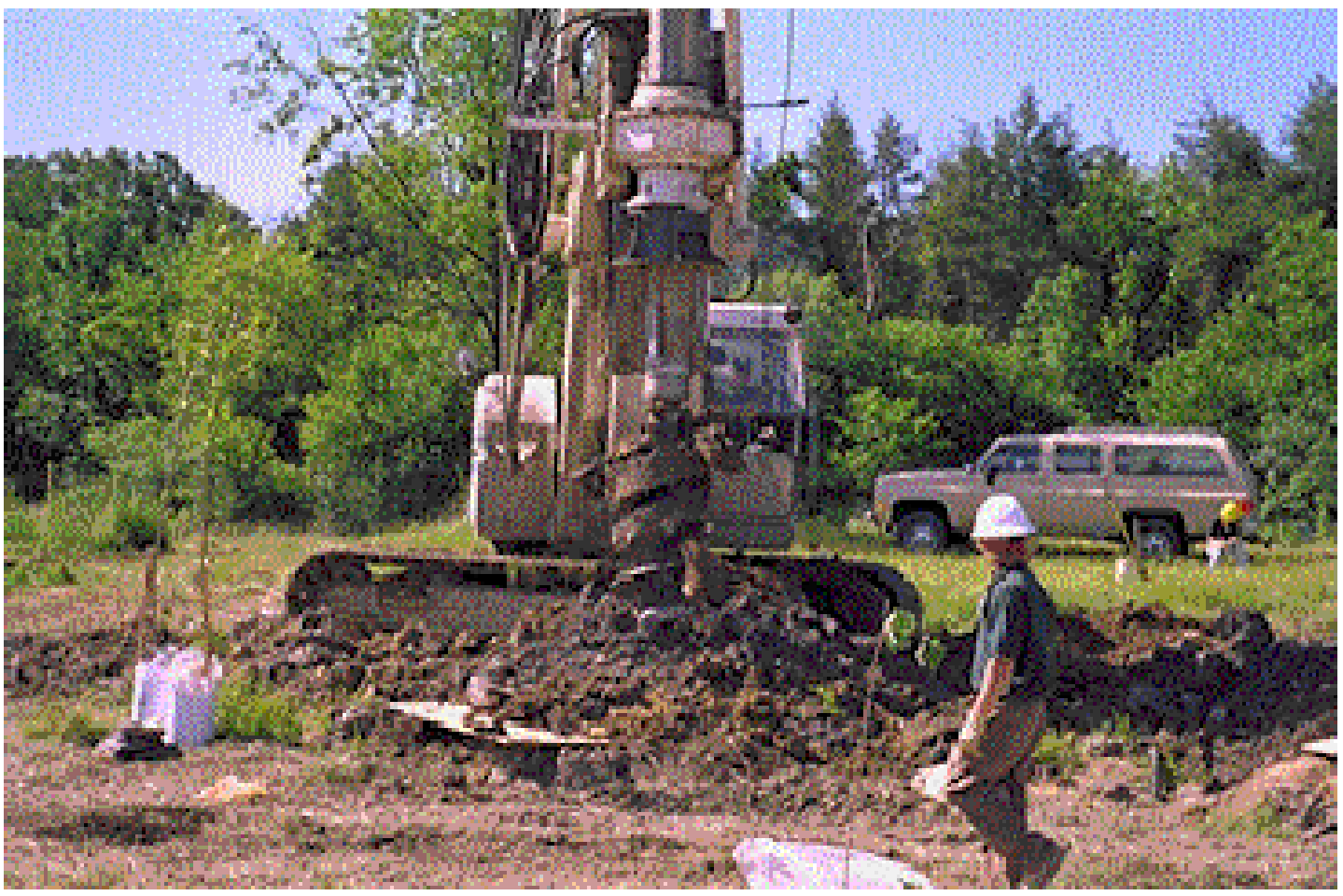

Figure 3: A borehole being drilled in the 317 Hydraulic Control Area. 
APPENDIX F

PARTICIPANT ROSTER 


\section{APPENDIX F}

\begin{tabular}{|c|c|c|c|c|c|}
\hline \multicolumn{6}{|c|}{ Participant Roster } \\
\hline No. & NAME & ADDRESS & PHONE & E-MAIL & TEAM \\
\hline 1. & $\begin{array}{l}\text { Adriano, } \\
\text { Domy }\end{array}$ & $\begin{array}{l}\text { Savannah River } \\
\text { Ecology Lab }\end{array}$ & (803) 725-5834 & adriano@srel.edu & $\begin{array}{l}\text { Soil// } \\
\text { Sequestration }\end{array}$ \\
\hline 2. & $\begin{array}{l}\text { Aitchenson, } \\
\text { Eric }\end{array}$ & Ecolotree, Inc. & (319) 358-9753 & ecolotreee@aol.com & Groundwater \\
\hline 3. & Angle, J. Scott & Univ. Maryland & (301) 405-2462 & ja35@umail.umd.edu & $\begin{array}{l}\text { Soil// } \\
\text { Sequestration }\end{array}$ \\
\hline 4. & $\begin{array}{l}\text { Ainsworth, } \\
\text { Calvin }\end{array}$ & PNNL & (509) 375-2670 & calvin.ainsworth@pnl.gov & $\begin{array}{l}\text { Soil/ } \\
\text { Sequestration } \\
\text { (Team Lead) }\end{array}$ \\
\hline 5. & Banuelos, Gary & USDA & (209) 453-3115 & banuelos@asrr.arsusda.gov & Soil/Removal \\
\hline 6. & Blake, John & $\begin{array}{l}\text { Forest Service, } \\
\text { SRS }\end{array}$ & (803) 725-8721 & j.blake@srs.gov & Monitoring \\
\hline 7. & \begin{tabular}{|l} 
Blaylock, \\
Michael
\end{tabular} & Phytotech & $\begin{array}{c}(732) 438-0900 \\
\text { ext. } 13\end{array}$ & soilrx@aol.com & $\begin{array}{l}\text { Soil// } \\
\text { Sequestration }\end{array}$ \\
\hline 8. & \begin{tabular}{|l|} 
Brigmon, \\
Robin
\end{tabular} & $\begin{array}{l}\text { Savannah River } \\
\text { Technology Center }\end{array}$ & (803) 557-7719 & r03.brigmon@srs.gov & \begin{tabular}{|l}
$\begin{array}{l}\text { Soil// } \\
\text { Sequestration }\end{array}$ \\
\end{tabular} \\
\hline 9. & Blundy, Robert & SRS & ) $952-6788$ & robert.blundy@srs.gov & Groundwater \\
\hline 10. & Brown, Jay & INEEL & (208) 526-0980 & jtb@inel.gov & $\begin{array}{l}\text { Float } \\
\text { (Organizer) }\end{array}$ \\
\hline 11. & Chaney, Rufus & USDA & (301) 504-8324 & rchaney@asrr.arsusda..gov & Monitoring \\
\hline 12. & Coia, Michael & ART Inc. & (610) 896-9946 & coiaart@bellatlantic.net & Soil/Removal \\
\hline 13. & $\begin{array}{l}\text { Collazo, } \\
\text { Yvette }\end{array}$ & DOE-ARG & (630) $252-2102$ & Yvette.collazo@ch.doe.gov & Float \\
\hline 14. & Corey, Jack & SRS & (803) 725-1134 & john.corey@srs.gov & $\begin{array}{l}\text { Float } \\
\text { (Organizer) }\end{array}$ \\
\hline 15. & Cornish, Jay & MSE & (406) 494-7100 & jcornish@mse-ta.com & $\begin{array}{l}\text { Soil// } \\
\text { Sequestration }\end{array}$ \\
\hline 16. & $\begin{array}{l}\text { Di Benedetto, } \\
\text { John }\end{array}$ & $\begin{array}{l}\text { Special } \\
\text { Technologies } \\
\text { Laboratory }\end{array}$ & (805) 681-2240 & dibeneja@nv.doe.gov & Monitoring \\
\hline 17. & $\begin{array}{l}\text { Dushenkov, } \\
\text { Slavik }\end{array}$ & Rutgers/AgBiotech & $\begin{array}{c}\text { (732) } 932-8165 \\
\text { ext. } 110\end{array}$ & dushenkov@aesop.rutgers.edu & Soil/Removal \\
\hline 18. & Ebbs, Steven & $\begin{array}{l}\text { Southern Illinois } \\
\text { University }\end{array}$ & (618) 536-2331 & ebbs@siu.edu & $\begin{array}{l}\text { Soil// } \\
\text { Sequestration }\end{array}$ \\
\hline 19. & Eberts, Sandra & USGS, $\mathrm{OH}$ & (614) 430-7748 & smeberts@usgs.gov & Monitoring \\
\hline 20. & Fan, Teresa & U.C. Davis, EMSP & (530) $752-1450$ & twfan@ucdavis.edu & $\begin{array}{l}\text { Soil// } \\
\text { Sequestration }\end{array}$ \\
\hline
\end{tabular}




\begin{tabular}{|c|c|c|c|c|c|}
\hline \multicolumn{6}{|c|}{ Participant Roster } \\
\hline No. & NAME & ADDRESS & PHONE & E-MAIL & TEAM \\
\hline 21. & Fellows, Bob & PNNL & (509) 375-2247 & robert.fellows@exchange.pnl.gov & $\begin{array}{l}\text { Soil// } \\
\text { Sequestration }\end{array}$ \\
\hline 22. & Francis, A.J. & $\mathrm{BNL}$ & (516) 344-4534 & francis1@bnl.gov & $\begin{array}{l}\text { Soil/ } \\
\text { Sequestration }\end{array}$ \\
\hline 23. & Fruchter, John & PNNL & (509) 376-3937 & john.fruchter@pnl.gov & Groundwater \\
\hline 24. & $\begin{array}{l}\text { Fuhrmann, } \\
\text { Mark }\end{array}$ & $\mathrm{BNL}$ & (516) 344-2224 & fuhrmann@bnl.gov & $\begin{array}{l}\text { Soil/ } \\
\text { Sequestration }\end{array}$ \\
\hline 25. & Gabel, Andrew & DOE-ARG & (630) 252-2213 & Andrew.gabel@ch.doe.gov & Float \\
\hline 26. & $\begin{array}{l}\text { Gatliff, } \\
\text { Edward }\end{array}$ & $\begin{array}{l}\text { Applied Natural } \\
\text { Sciences }\end{array}$ & (513) 895-6061 & egatliff@cinti.net & Groundwater \\
\hline 27. & Glenn, Anne & INEEL & (208) 526-0376 & awg@inel.gov & $\begin{array}{l}\text { Float } \\
\text { (Organizer) }\end{array}$ \\
\hline 28. & Goswami, Dib & $\begin{array}{l}\text { State of WA, } \\
\text { Dept Ecology }\end{array}$ & (509) 736-3015 & dgos461@ecy.wa.gov & $\begin{array}{l}\text { Soil// } \\
\text { Sequestration }\end{array}$ \\
\hline 29. & Helt, James & ANL-ET & (630) 252-7335 & Jhelt@anl.gov & Float \\
\hline 30. & $\begin{array}{l}\text { Hinchman, } \\
\text { Ray }\end{array}$ & ANL-ES & (630) 2523391 & hinchman@anl.gov & Groundwater \\
\hline 31. & Hulet, Greg & INEEL & (208) 526-0283 & hag@inel.gov & Soil/Removal \\
\hline 32. & Jastrow, Julie & ANL-ER & (630) 252-3226 & jdjastrow@anl.gov & Soil/Removal \\
\hline 33. & $\begin{array}{l}\text { Kauffman, } \\
\text { Jennifer }\end{array}$ & Enviro Issues & (206) 269-5041 & jkauffman@enviroissues.com & Facilitator \\
\hline 34. & King, Trudy & USGS Denver & (303) 236-1373 & tking@speclab.cr.usgs gov & Monitoring \\
\hline 35. & $\begin{array}{l}\text { Krstich, } \\
\text { Michael }\end{array}$ & EMS & (513) 697-6682 & mak@fuse.net & Soil/Removal \\
\hline 36. & $\begin{array}{l}\text { Kucharski, } \\
\text { Rafal }\end{array}$ & $\begin{array}{l}\text { Poland, Institute } \\
\text { for Ecology of } \\
\text { Industrial Areas }\end{array}$ & & sas@ietu.katowice.pl & Soil/Removal \\
\hline 37. & $\begin{array}{l}\text { Kuperberg, } \\
\text { Mike }\end{array}$ & \begin{tabular}{|l|} 
Florida State \\
University \\
\end{tabular} & (850) 644-5524 & mkupe@mailer.fsu.edu & $\begin{array}{l}\begin{array}{l}\text { Soil/Removal } \\
\text { (Team Lead) }\end{array} \\
\end{array}$ \\
\hline 38. & $\begin{array}{l}\text { Landmeyer, } \\
\text { Jim }\end{array}$ & $\begin{array}{l}\text { USGS, Columbus, } \\
\text { SC }\end{array}$ & (803) 750-6128 & jlandmey@usgs.gov & Monitoring \\
\hline 39. & Lasat, Mitch & $\begin{array}{l}\text { USDA- } \\
\text { ARA/Cornell }\end{array}$ & & Lasat.Mitch@epamail.epa.gov & Soil/Removal \\
\hline 40. & Lee, Scott & ANL-W & (208) 533-7829 & scott.lee@anlw.anl.gov & Soil/Removal \\
\hline 41. & Li, Yin-Ming & \begin{tabular}{|l} 
Viridian \\
Environmental \\
\end{tabular} & (301) 504-6550 & yli@asrr.arsusda.gov & Soil/Removal \\
\hline 42. & Lindgren, Eric & $\begin{array}{l}\text { Sandia National } \\
\text { Labs }\end{array}$ & (505) 844-3820 & erlindg@sandia.gov & Groundwater \\
\hline
\end{tabular}




\begin{tabular}{|c|c|c|c|c|c|}
\hline \multicolumn{6}{|c|}{ Participant Roster } \\
\hline No. & NAME & ADDRESS & PHONE & E-MAIL & TEAM \\
\hline 43. & $\begin{array}{l}\text { Matthern, } \\
\text { Gretchen }\end{array}$ & INEEL & (208) 526-8747 & gtn@inel.gov & $\begin{array}{l}\begin{array}{l}\text { Float } \\
\text { (Organizer) }\end{array} \\
\end{array}$ \\
\hline 44. & Mays, David & $\begin{array}{l}\text { Alabama A\&M } \\
\text { State Univ. }\end{array}$ & (256) 858-4227 & Aamcrh01@aamu.edu & $\begin{array}{l}\text { Soil// } \\
\text { Sequestration }\end{array}$ \\
\hline 45. & $\begin{array}{l}\text { McIntyre, } \\
\text { Terry }\end{array}$ & \begin{tabular}{|l} 
Environment \\
Canada
\end{tabular} & (819) 994-1105 & Terry.McIntyre@EC.GC.CA & Groundwater \\
\hline 46. & $\begin{array}{l}\text { McMullin, } \\
\text { Scott }\end{array}$ & SRS-DOE & (803) 725-9596 & scott.mcmullin@srs.gov & $\begin{array}{l}\text { Float } \\
\text { (Organizer) }\end{array}$ \\
\hline 47. & \begin{tabular}{|l} 
Miller, \\
Michael
\end{tabular} & ANL-ER & (630) 252-3395 & rmmiller@anl.gov & $\begin{array}{l}\text { Soil// } \\
\text { Sequestration }\end{array}$ \\
\hline 48. & Mueller, Bob & NJ DEP & (609) 984-3910 & bmueller@dep.state.nj.us & Monitoring \\
\hline 49. & Negri, Cristina & ANL-ES & (630) 252-9662 & negri@anl.gov & $\begin{array}{l}\text { Float } \\
\text { (Organizer) }\end{array}$ \\
\hline 50. & Ow, David & $\begin{array}{l}\text { USDA-ARA- } \\
\text { EMSP }\end{array}$ & (510) 559-5909 & ow@pgec.ars.usda.gov & Groundwater \\
\hline 51. & Pflug, Dale & ANL-EAD & (630) 252-6682 & dpflug@anl.gov & Float \\
\hline 52. & $\begin{array}{l}\text { Punshon, } \\
\text { Tracy }\end{array}$ & SRS Ecology Lab & (803) 725-5956 & punshon@pop3.srel.edu & Monitoring \\
\hline 53. & Quinn, John & ANL-EAD & (630) 2525357 & quinnj@anl.gov & Groundwater \\
\hline 54. & $\begin{array}{l}\text { Reynolds, } \\
\text { Mike }\end{array}$ & $\begin{array}{l}\text { DoD-USACE, } \\
\text { CRREL }\end{array}$ & (603) 646-4394 & reynolds@crrel.usace.army.mil & Monitoring \\
\hline 55. & Richter, Peter & $\begin{array}{l}\text { Technical Univ. } \\
\text { Budapest, Hungary }\end{array}$ & & & Monitoring \\
\hline 56. & Rock, Steven & USEPA & (513) 569-7149 & rock.steven@epa.gov & $\begin{array}{l}\text { Groundwater } \\
\text { (Team Lead) }\end{array}$ \\
\hline 57. & Rose, Keith & EPA-Region 10 & (206) 553-7721 & rose.keith@epamail.epa.gov & Soil/Removal \\
\hline 58. & Ruesche, Paul & EPA-Region 5 & (312) 886-7598 & ruesch.paul@epa.gov & Groundwater \\
\hline 59. & $\begin{array}{l}\text { Sas- } \\
\text { Nowosielska, } \\
\text { Aleksandra }\end{array}$ & $\begin{array}{l}\text { Poland, Institute } \\
\text { for Ecology of } \\
\text { Industrial Areas }\end{array}$ & & sas@ietu.katowice.pl & Soil/Removal \\
\hline 60. & \begin{tabular}{|l|} 
Schalk, \\
Charles
\end{tabular} & USGA & (614) 430-7745 & cwschalk@usgs.gov & Monitoring \\
\hline 61. & $\begin{array}{l}\text { Schuerger, } \\
\text { Andrew }\end{array}$ & Dynamic Corp. & (407) 560-7402 & schuerger@bellsouth.net & Monitoring \\
\hline 62. & Sturchio, Neil & ANL-ER & (630) 252-3986 & sturchio@anl.gov & Groundwater \\
\hline 63. & \begin{tabular}{|l|} 
Smalley, \\
Richard
\end{tabular} & $\begin{array}{l}\text { WPI/Savannah } \\
\text { River }\end{array}$ & $\begin{array}{c}803) 652-8020 \\
\text { ext. } 36 \\
\end{array}$ & richard_smalley@ak.wpi.org & Float \\
\hline 64. & Terry, Norman & U.C. Berkley & (510) 642-3510 & nterry@ nature.berkeley.edu & Soil/Removal \\
\hline
\end{tabular}




\begin{tabular}{|c|c|c|c|c|c|}
\hline \multicolumn{6}{|c|}{ Participant Roster } \\
\hline No. & NAME & ADDRESS & PHONE & E-MAIL & TEAM \\
\hline 65. & Voos, Gerald & WPI & $\begin{array}{c}\text { (803) } 652-8020 \\
\text { ext. } 27\end{array}$ & gerard_voos@ak.wpi.org & Float \\
\hline 66. & Waugh, Jody & GJO & (970) 248-6431 & ¡ody.waugh@doegjpo com & \begin{tabular}{|l|} 
Monitoring \\
(Team Lead)
\end{tabular} \\
\hline 67. & $\begin{array}{l}\text { Wullschleger, } \\
\text { Stan }\end{array}$ & $\begin{array}{l}\text { Environmental } \\
\text { Sciences } \\
\text { Division;ORNL } \\
\end{array}$ & (423) 574-7839 & w5d@ornl.gov & Groundwater \\
\hline 68. & Yancey. Neal & INEEL & (208) 526-5157 & yancna@inel.gov & Groundwater \\
\hline
\end{tabular}


APPENDIX G SUPPORTING DOCUMENTS 


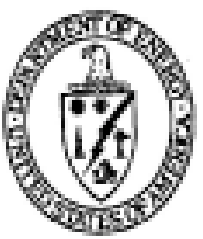

\section{Department of Energy Savarnah Fiver Operafions Omice P.O. Boox A \\ Alken, South Carolina 23802}

September 28, 1999

To: Invitee

SUBJECT: Invitation to Phytoremediation Workshop

The U.S. Department of Energy, Office of Technology Development and Long-Term Stewardship, and the Subsurface Contaminants Focus Area (SCFA) is sponsoring a Phytoremediation Workshop to identify potential areas for research and technology development addressing phytoremediation of inorganic contaminants. You are invited to participate in this invitation-only workshop, which is scheduled for November 30 through December 2, 1999, at Argonne National Laboratory (ANL-E) in Chicago, llinois.

The purpose for this workshop is to evaluate four primary areas of phytoremediation to identify the existing baseline and areas for further research. Each area will be addressed in a separate breakout session during the workshop. - These four primary areas are:

1. Removal of contaminants from the soil

2. Remuval of contaminants from the groundwater

3. Sequestration of contaminants

4. Phytoremediation as a monitoring technique

The workshop objectives are as follows:

1. Status the existing baseline, including technological maturation.

2. Identify areas for future potential research.

3. Identify the key issues and recommendations for issue resolution.

4. Reconmend a strategy for maturing key aspects of phytoremediation.

5. Improve communication and collaboration among organizations currently involved in phytoremediation research.

6. Identify technical barriers to making phytoremediation commercially successful in more areas.

The team leads will work with the workshop organizers to finalize the area of discussion for each team and to select participants for each team.

As this workshop is by invitation only, please respond to Anae Glenn by October 8,1999 , as to your availability and willingness to participate. The agenda and supporting information will be transmitted to you upon responding aftirmatively to this invitation. If you have any questions or suggestions, please contact Anne Glenn (208/526-0376; awg@inel.gov) or Cristina Negri (630/252-9662; negri@anl.gov).

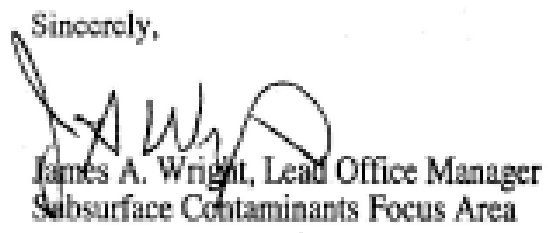

OF-99-06? 


\section{AGENDA \\ WORKSHOP ON PHYTOREMEDIATON OF INORGANIC CONTAMINANTS \\ November 30 to December 2, 1999 \\ Argonne National Laboratory, APS Conference Center}

\section{Tuesday November 30, 1999}

5:00 - 5:30 p.m. Team Lead and Facilitator Meeting

- Answer questions, confirm schedule, view meeting rooms

5:30 - 6:30 p.m. Registration

- Schedule, list of participants, map of facilities, copy of overheads

6:30 - 8:00 p.m. Introduction and Overview, Box Dinner

- Welcome (Yoon Chang and Timothy Crawford, Argonne)

- Workshop mechanics: 5 min (EnviroIssues Representative)

- People introduction: 10 min (Gretchen Matthern)

- Purpose of workshop: 20 min (Scott McMullin)

- Description of site needs: 20 min (Jack Corey)

- Present Topics: 20 min (Team Leaders)

\section{Wednesday December 1, 1999}

8:00 - 9:00 a.m. Plenary Session: State of the Art presentations

(Team leaders $15 \mathrm{~min}$ each)

9:30 - 11:30 a.m. Separate into Teams, Begin Discussion

11:30 - 2:00 p.m. Lunch and Tour

2:00 - 4:30 p.m. Separate into Teams: Continue Discussion and Draft Reports

4:30 - 5:00 p.m. Team Leader and Facilitator Status Meeting

\section{Thursday December 2, 1999}

9:00 - 11:30 a.m. Plenary Session: Presentations \& Discussion of Team Drafts

- 15 min presentation, plus 10 min questions per group

11:30 - 12:30 p.m. Lunch

- 30 min. general discussion

12:30 - 2:00 p.m. $\quad$ Separate into Teams:

- Revise Plan of Action

- Prepare Summary

2:00 - 2:30 p.m. Plenary Session:

- Present Summaries, 5 min per team

2:30 - 3:00 p.m. Closing Remarks (Scott McMullin)

3:00 - 7:00 p.m. Team Leader Write-ups 


\section{APPENDIX H DEFINITIONS}




\section{APPENDIX H DEFINITIONS}

Bioavailability: Nutrients in a chemical form that can be taken up and used by plants to grow and reproduce.

Biomagnification: The increase in the concentration of toxic substances as one moves up the food chain.

Evapotranspiration: The transfer of water from the earth into the atmosphere by (1) evaporation from surface water and soil and (2) transpiration from vegetation.

Exudates: Release of soluble organic matter from the roots of plants to enhance availability of nutrients or as a byproduct of fine root degradation.

Humification: Microbial transformation of organic matter (dead plant and animal tissues) into humic material which can form stable complexes with some metals influencing the availability of these complexes to plants and microorganisms.

Hyperaccumulation: Accumulate abnormally high quantities of elements from soils by plants.

Phytoextraction: The use of plants at waste sites to accumulate metals into the harvestable above-ground portion of the plant and, thus, to decontaminate soils.

Phytosequestration: The inhibition or prevention of normal migration of contaminants by plants.

Phytostabilization: The absorption and precipitation of contaminants, principally metals by plants, reducing their mobility and preventing their migration to groundwater (leaching) or air (wind transport), or entry into the food chain.

Rhizosphere: The soil profile in close contact with roots of plants, usually taken to be the soil within $1 \mathrm{~mm}$ of roots and fine roots. 


\section{APPENDIX I SOURCES OF ADDITIONAL INFORMATION}




\title{
APPENDIX I \\ SOURCES OF ADDITIONAL INFORMATION
}

\author{
U.S. Department of Energy - Subsurface Contaminants Focus Area \\ Scott McMullin \\ DOE - Savannah River \\ Product Line Manager - Source Term Containment/Metals and Rads Product Line \\ (803) 725 - 9596 \\ E-mail: scott.mcmullin@ srs.gov
}

SCFA web site: http://www.envnet.org/scfa

\section{Interstate Technology Regulatory Cooperation (ITRC) Work Group}

(A national coalition that focuses on creating tools and strategies to reduce interstate barriers to the deployment of innovative environmental technologies)

Phytoremediation Work Team (recently drafted a phytoremediation decision tree document)

Bob Mueller, Work Team Lead

NJ DEP

(609) 984-3910

E-mail: bmueller@dep.state.nj.us

Dib Goswani, Work Team Lead

WA Dept. of Ecology

(509) 736-3015

E-mail: dgos461@ecy.wa.gov

ITRC web site: http://www.itrcweb.org

\section{Remedial Technologies Development Forum (RTDF)}

(A consortium of partners from industry, government and academia working together to develop safer, more effective, and less costly characterization and treatment technologies)

Phytoremediation of Organics Action Team (may serve as model for future inorganics team)

Steve Rock, Co-Chair

U.S. Environmental Protection Agency

National Risk Management Research Laboratory

(513) 569-7149

E-mail: rock.steven@epa.gov

Lucinda Jackson, Co-chair

Chevron Corporation

(510) 242-1047

E-mail: luaj@chevron.com

RTDF web site: http://www.rtdf.org 
U.S. EPA - Technology Information Office

(Operates TechDirect, a free e-mail subscription service that reports new remediation documents)

Phytoremediation Resource Guide (EPA 542-B-99-003)

This guide provides abstracts of more that 100 phytoremediation overviews, field studies and demonstrations, research articles and Internet resources. (May 1999, 56 p.)

View or download from http://clu-in.org/techpubs.htm

Can also be ordered by calling (800) 490-9198 or (513) 489-8190. 